OPEN ACCESS

Edited by:

Nicolas Unsain,

Medical Research Institute Mercedes and Martín Ferreyra (INIMEC),

Argentina

Reviewed by:

Adriana Di Polo,

Université de Montréal, Canada Yasushi Kitaoka,

St. Marianna University School of Medicine, Japan

${ }^{*}$ Correspondence:

David J. Calkins

david.j.calkins@vumc.org

${ }^{\dagger}$ These authors have contributed equally to this work

Specialty section:

This article was submitted to Cellular Neuropathology,

a section of the journal

Frontiers in Cellular Neuroscience

Received: 06 September 2020

Accepted: 15 December 2020

Published: 11 January 2021

Citation:

Risner ML, McGrady NR, Boal AM,

Pasini S and Calkins DJ

(2021) TRPV1 Supports Axogenic

Enhanced Excitability in Response to

Neurodegenerative Stress.

Front. Cell. Neurosci. 14:603419.

doi: 10.3389/fncel.2020.603419

\section{TRPV1 Supports Axogenic Enhanced Excitability in Response to Neurodegenerative Stress}

\author{
Michael L. Risner ${ }^{\dagger}$, Nolan R. McGrady ${ }^{\dagger}$, Andrew M. Boal, Silvia Pasini \\ and David J. Calkins*
}

Department of Ophthalmology and Visual Sciences, Vanderbilt Eye Institute, Vanderbilt University Medical Center, Nashville, TN, United States

Early progression in neurodegenerative disease involves challenges to homeostatic processes, including those controlling axonal excitability and dendritic organization. In glaucoma, the leading cause of irreversible blindness, stress from intraocular pressure (IOP) causes degeneration of retinal ganglion cells (RGC) and their axons which comprise the optic nerve. Previously, we discovered that early progression induces axogenic, voltage-gated enhanced excitability of RGCs, even as dendritic complexity in the retina reduces. Here, we investigate a possible contribution of the transient receptor potential vanilloid type 1 (TRPV1) channel to enhanced excitability, given its role in modulating excitation in other neural systems. We find that genetic deletion of Trpv1 (Trpv1-/-) influences excitability differently for RGCs firing continuously to light onset ( $\alpha \mathrm{ON}$-Sustained) vs. light offset ( $\alpha$ OFF-Sustained). Deletion drives excitability in opposing directions so that Trpv1-1- RGC responses with elevated IOP equalize to that of wild-type (WT) RGCs without elevated IOP. Depolarizing current injections in the absence of light-driven presynaptic excitation to directly modulate voltage-gated channels mirrored these changes, while inhibiting voltage-gated sodium channels and isolating retinal excitatory postsynaptic currents abolished both the differences in lightdriven activity between WT and Trpv1 ${ }^{-1-}$ RGCs and changes in response due to IOP elevation. Together, these results support a voltage-dependent, axogenic influence of Trpv1 $1^{-1-}$ with elevated IOP. Finally, Trpv1-1- slowed the loss of dendritic complexity with elevated IOP, opposite its effect on axon degeneration, supporting the idea that axonal and dendritic degeneration follows distinctive programs even at the level of membrane excitability.

Keywords: TRPV1, neurodegeneration, glaucoma, retinal ganglion cells, axon, dendritic pruning

\section{INTRODUCTION}

Age-related neurodegenerative diseases involve diverse etiologies and phenotypes but share similar patterns of progression (Coleman, 2005; Morfini et al., 2009). Early pathogenesis involves challenges to axonal physiology, including degradation of active transport and accumulation of cytoskeletal components, while somatic and postsynaptic target structures degrade more slowly (Collard et al., 1995; Li and Li, 2004; Stokin et al., 2005; Her and Goldstein, 2008; Crish et al., 2010; Risner et al., 2018). In some instances, early progression includes modified patterns of excitation and excitability. For example, hippocampal brain regions in patients with mild cognitive impairment demonstrate 
hyperactivation during memory tasks compared to decreased activation in patients with more advanced Alzheimer's disease (Dickerson et al., 2005), while neurons in transgenic models of the disease show increased action potential generation (Sanchez et al., 2012; Kerrigan et al., 2014; Palop and Mucke, 2016). Similarly, neurons in models of Huntington's disease and amyotrophic lateral sclerosis demonstrate lower thresholds for spiking accompanied by increased firing and depolarization of the resting membrane potential (RMP; van Zundert et al., 2008; Benraiss et al., 2016; Fogarty, 2018).

Recently, we discovered similar changes in retinal ganglion cell (RGC) excitability in an inducible model of glaucomatous optic neuropathy (or glaucoma), the leading cause of irreversible blindness worldwide (Tham et al., 2014). The disease involves sensitivity to intraocular pressure (IOP), which stresses retinal ganglion cell (RGC) axons where they exit the eye to form the optic nerve (Calkins, 2012). Modest, short-term elevations in IOP transiently enhance RGC excitability, including their light response, even as dendritic arbors lose complexity (Weitlauf et al., 2014; Risner et al., 2018). Enhancement involves IOP-dependent upregulation and translocation of voltage-gated sodium $(\mathrm{NaV})$ channels along the unmyelinated axon segment in the retina, in particular, the $\mathrm{Na}_{V} 1.6$ subunit (Risner et al., 2018). Interestingly, genetic ablation of the transient receptor potential vanilloid type 1 (TRPV1) channel $\left(\operatorname{Tr} p v 1^{-/-}\right)$increased $\mathrm{Na}_{\mathrm{V}} 1.6$ and excitability of RGC axons in the optic nerve following elevations in IOP (McGrady et al., 2020), while accelerating axon degeneration (Ward et al., 2014). Finally, elevated IOP changes TRPV1's net influence on RGC physiology from reducing to promoting excitation (Ward et al., 2014; Weitlauf et al., 2014).

In many neuronal tissues, including the retina, TRPV1 signals stress-related stimuli by modulating excitation through $\mathrm{Ca}^{2+}$ driven currents (Rong et al., 2004; Scotland et al., 2004; Jones et al., 2005; Vriens et al., 2009; Sappington et al., 2015). In glaucoma models, RGCs that depolarize to light onset (ON cells) or light offset (OFF cells) may show different susceptibility to elevated IOP (Della Santina et al., 2013; El-Danaf and Huberman, 2015; Ou et al., 2016). Here, we investigate how $\operatorname{Trp} v 1^{-/-}$influences enhanced excitability of a major class of ON and OFF RGCs, the $\alpha$-Sustained type (Pang et al., 2003; Della Santina et al., 2013; Ou et al., 2016; Krieger et al., 2017). By comparing wild-type (WT) and Trp $v 1^{-/-}$RGC responses to light, we find that TRPV1 has opposing effects on excitability for $\alpha \mathrm{ON}$-Sustained ( $\alpha \mathrm{ON}-\mathrm{S}$ ) and $\alpha$ OFF-Sustained ( $\alpha$ OFF-S) RGCs following short-term elevations in IOP. For each type, injecting depolarizing currents to drive voltage-gated channels in conditions that bypass presynaptic activity mimicked the light-induced differences in RGC response. Conversely, we found silencing $\mathrm{NaV}$ channels eliminated the differences in the light-evoked activity of WT and Trp $v 1^{-/-} \alpha$ RGCs, implicating an axogenic source of TRPV1's influence on RGC physiology. Finally, $\operatorname{Trp} v 1^{-/-}$ slowed the loss of dendritic complexity with elevated IOP, opposite of its effect on axon degeneration (Ward et al., 2014; McGrady et al., 2020). The opposing influence of $\operatorname{Trp} v 1^{-/-}$ on the dendritic organization and axon physiology reinforces the concept that dendritic and axonal degeneration follows distinct programs.

\section{MATERIALS AND METHODS}

\section{Animals}

Adult male $\operatorname{Trpv1} 1^{-/-}\left(\mathrm{B} 6.129 \times 1-\operatorname{Trpv1}^{\mathrm{tm} 1 \mathrm{Jul} / \mathrm{J})}\right.$ mice (1.5-2 months old, $n=18$ ) were obtained from The Jackson Laboratory (Bar Harbor, ME, USA), while the appropriate WT background strain $\mathrm{C} 57 \mathrm{Bl} / 6$ mice were purchased from Charles River Laboratories (male, 1.5-2 months old, $n=18$, Wilmington, MA, USA). The Trpv1 $1^{-/-}$mice have a targeted mutation causing a non-functional truncated form of TRPV1 (Caterina et al., 2000; Ren et al., 2019; Stanford et al., 2019). Mice were maintained in $12 \mathrm{~h}$ light/dark cycles, and animals were allowed water and standard rodent chow as desired. All animal experiments were approved by the Vanderbilt University Medical Center Institutional Animal Care and Use Committee.

\section{Genotyping and Intraocular Pressure Elevation}

$\operatorname{Tr} p v 1^{-/-}$animals were genotyped before performing experiments, following our protocol (Ward et al., 2014; Weitlauf et al., 2014; Sappington et al., 2015) using primers recommended by the vendor. The mutant forward primer was TAA AGC GCA TGC TCC AGA CT compared to the WT forward primer of TGG CTC ATA TTT GCC TTC AG. The common primer was CAG CCC TAG GAG TTG ATG GA (Integrated DNA Technologies, Coralville, IA, USA). DNA gel electrophoresis of $\operatorname{Trp} v 1^{-/-}$animals showed a single band at $176 \mathrm{bp}$ indicative of truncated TRPV1 (Caterina et al., 2000; Ren et al., 2019; Stanford et al., 2019), while WT showed a single band at $289 \mathrm{bp}$ indicative of the native protein (Figure 1A). We verified this pattern in each animal utilized. Baseline IOP was measured bilaterally in anesthetized (2.5\% isoflurane) mice using TonoPen XL (Reichert Technologies, Depew, NY, USA) for 1-2 days before experimental manipulation. Baseline IOP measurements were averaged (day 0). After baseline IOP measurements, the unilateral elevation of IOP was induced by injecting $1.5 \mu \mathrm{l}$ of $15 \mu \mathrm{m}$ polystyrene microbeads (Invitrogen, Carlsbad, CA, USA) into the anterior chamber; the fellow eye received an equal volume of sterile saline to serve as the control. We measured IOP 2-3 times per week for 2 weeks as described previously (Crish et al., 2010; Weitlauf et al., 2014; Risner et al., 2018; Figure 1B).

\section{Retinal Ganglion Cell Physiology}

After euthanizing animals (cervical dislocation), eyes were enucleated, and the retinas were dissected out under long-wavelength illumination $\left(630 \mathrm{~nm}, 800 \mu \mathrm{W} / \mathrm{cm}^{2}, \mathrm{FND} / \mathrm{FG}\right.$, Ushio, Cypress, CA, USA). Retinas were placed in carbogensaturated Ames' medium (US Biologic, Memphis, TN, USA) supplemented with $20 \mathrm{mM}$ glucose and $22.6 \mathrm{mM} \mathrm{NaHCO}$ ( $\mathrm{pH} 7.4,290$ Osm). Whole retinas were mounted singly onto a physiological chamber and perfused at a rate of $2 \mathrm{ml} / \mathrm{min}$ with Ames' medium maintained at $35^{\circ} \mathrm{C}$ (Model TC-344C, Warner Instruments, Hamden, CT, USA). 
Retinal ganglion cells (RGC) were viewed under DIC using an Andor CCD camera attached to an Olympus BX50 upright microscope at $40 \times$. RGCs were targeted for intracellular recording with pipettes fabricated from borosilicate glass (Sutter Instruments, Novato, CA, USA) and filled with (in $\mathrm{mM}$ ): $125 \mathrm{~K}$-gluconate, $10 \mathrm{KCl}, 10 \mathrm{HEPES}, 10 \mathrm{EGTA}, 4 \mathrm{Mg}$-ATP, $1 \mathrm{Na}-\mathrm{GTP}$, and 0.1 ALEXA 555 (Invitrogen, Carlsbad, CA, USA). The intracellular solution $\mathrm{pH}$ was 7.35 and osmolarity was 285 Osm. Pipette containing intracellular solution had a resistance between 4-8 M $\Omega$. Whole-cell signals were amplified (Multiclamp 700B, Molecular Devices, San Jose, CA, USA) and digitized at a sampling rate of $50 \mathrm{kHz}$ (Digidata 1550A, Molecular Devices, San Jose, CA, USA). Access resistance was monitored and maintained $\leq 30 \mathrm{M} \Omega$.

During a typical experiment, we measured RMP, spontaneous spike activity, light-evoked spike activity (full-field $365 \mathrm{~nm}$, $300 \mu \mathrm{W} / \mathrm{cm}^{2}$, 3-s duration, Roithner Lasertechnik, Vienna Austria), and current-evoked spike activity while clamping the cell at $0 \mathrm{pA}$. In a subset of experiments, we measured lightevoked postsynaptic currents under voltage clamp $(-65 \mathrm{mV})$ while blocking $\mathrm{NaV}$ channels with tetrodotoxin (1 $\mu \mathrm{m}$, TTX). In another subset of experiments, we assessed the influence of TRPV1 antagonism by iodoresiniferatoxin (IRTX, $100 \mathrm{nM}$, Tocris, Bristol, UK) on light-evoked spiking. After physiology, retinas were placed in $2 \%$ paraformaldehyde (PFA) at $4^{\circ} \mathrm{C}$ for $24 \mathrm{~h}$.

\section{Immunohistochemistry, Imaging, and Dendritic Morphological Analysis}

Following fixation, retinas were immunolabeled for non-phosphorylated neurofilament $\mathrm{H}$ (SMI-32, 1:1,000; BioLegend, San Diego, CA, USA) and choline acetyltransferase (ChAT, 1:500; Millipore, Burlington, MA, USA). Retinas were first blocked in 5\% normal donkey serum for $2 \mathrm{~h}$ and then incubated in primary antibodies for 3 days at $4^{\circ} \mathrm{C}$. An Olympus FV1000 inverted microscope was used to obtain micrographs of RGC profiles en montage. After imaging, RGC dendritic morphologies were hand traced in Adobe Photoshop, and we measured total dendritic length, number of branching points, and complexity by Sholl analysis (Risner et al., 2018). The total dendritic length was defined as the sum of all dendritic lengths. A branch point was defined as the point of bifurcation of a dendrite from a parent dendrite. We also determined dendritic complexity using Sholl analysis (ImageJ version $1.53 \mathrm{c}$ ), which measures all dendritic crossings within $10 \mu \mathrm{m}$ concentric circles from the soma to distal dendritic tips $(\sim 300 \mu \mathrm{m})$.

\section{Statistical Analysis}

Data are presented as mean \pm standard error of the mean (SEM). Graphs were made using Sigma Plot Version 14 (Systat, San Jose, CA, USA) or Graphpad Version 8.0 (Graphpad, San Diego, CA, USA). Statistical analyses were performed using Sigma Plot or Graphpad. Outlier analysis was performed using Grubbs' test (Graphpad Software, San Diego, CA, USA). After outlier analysis, we determined if data were normal vs. lognormal. If all datasets to be compared best fit a lognormal distribution, data were transformed by taking the logarithm (base 10) of all numbers in the datasets (Choi, 2016). For data that fit a normal distribution or transformed, we performed parametric statistics (Student's $t$-tests, ANOVAs). Otherwise, we performed non-parametric statistics (Mann-Whitney tests, Kruskal-Wallis tests). Statistical significance was defined as $p \leq 0.05$.

\section{RESULTS}

\section{The Influence of Trpv1-/- on $\alpha$ ON-Sustained RGC Excitability With Elevated IOP}

We confirmed the genotype of $\operatorname{Trpv1} 1^{-/-}$mice utilized in these studies by identification of the truncated gene product as described (Figure 1A; Sappington et al., 2009, 2015; Ward et al., 2014; Weitlauf et al., 2014). Daily IOP did not differ between $\operatorname{Trp} v 1^{-/-}$and WT mice for either control (Ctrl; saline-injected) eyes or eyes receiving a single unilateral injection of polystyrene microbeads for 2 weeks $(p=0.99)$. Microbead injection elevated IOP significantly for both WT (+33\%) and Trpv1 ${ }^{-/-}(+36 \%)$ eyes compared to their respective control eyes $(p \leq 0.003$; Figure 1B), consistent with our earlier studies (Ward et al., 2014; Weitlauf et al., 2014). In this study, our WT control group consisted of RGCs from naïve and saline-injected eyes. We did not detect a significant difference in light responses of RGCs from WT naïve vs. saline-injected eyes $(p \geq 0.61)$.

To assess the impact of $\operatorname{Tr} p v 1^{-/-}$on RGC light responses, we identified $\alpha \mathrm{ON}$-Sustained ( $\alpha \mathrm{ON}-\mathrm{S}$ ) cells using established morphological and physiological criteria (Coombs et al., 2006; Della Santina et al., 2013; Bleckert et al., 2014; Schmidt et al., 2014; Baden et al., 2016; Ou et al., 2016; Risner et al., 2018, 2020). In WT retinas, these RGCs strongly express SMI-32 and have large cell bodies with expansive dendritic fields that ramify narrowly in the ON sublamina of the inner plexiform layer (IPL), proximal to bands of ChAT labeling (Figure 2A). In response to light, these cells produce a sustained train of action potentials (Figure 2B). While $\alpha \mathrm{ON}-\mathrm{S}$ RGCs in $\operatorname{Tr} p v 1^{-/-}$ retinas appear smaller, they too strongly express SMI-32 and have similar dendritic morphology and branching (Figure 2C). Their response to light is also sustained though apparently more robust than that of WT $\alpha \mathrm{ON}-\mathrm{S}$ RGCs (Figure 2D). When quantified, the light response of $\operatorname{Trp} v 1^{-/-} \alpha \mathrm{ON}-\mathrm{S}$ RGCs did indeed significantly exceed that of WT, for both mean firing rate $(+50 \%, p<0.001)$ and peak firing rate $(+45 \%$, $p=0.02$; Figures $2 \mathrm{E}, \mathbf{F})$. Also, $\alpha \mathrm{ON}-\mathrm{S}$ RGCs from $\operatorname{Tr} p v 1^{-/-}$ retinas demonstrated a significantly more depolarized RMP than their WT counterparts $(p=0.03$; Figure $2 \mathrm{~F})$. The difference in light response between WT and $\operatorname{Tr} p v 1^{-/-} \alpha \mathrm{ON}-\mathrm{S}$ RGCs is largely due to the absence of TRPV1 activity rather than a compensatory developmental response to $\operatorname{Tr} p v 1^{-/-}$. Bath application of the TRPV1 receptor-specific antagonist iodoresiniferatoxin (IRTX) increased the mean light response of naïve WT RGCs, while also depolarizing the RMP (Figures 2G,H). However, the lightevoked peak firing rate of $\alpha \mathrm{ON}-\mathrm{S}$ RGCs was unaffected by IRTX (Figures 2G, H).

We next asked how $\operatorname{Trp} v 1^{-/-}$influences excitability for $\alpha$ ON-S RGCs stressed by 2 weeks of elevated IOP. Spontaneous 


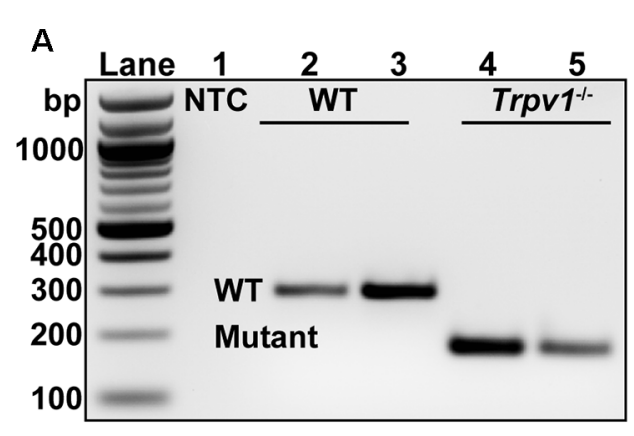

B

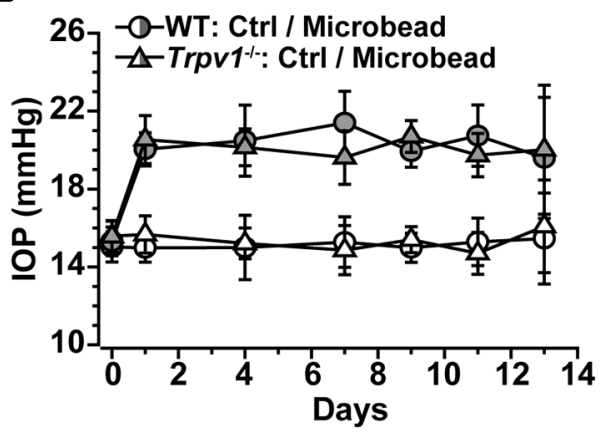

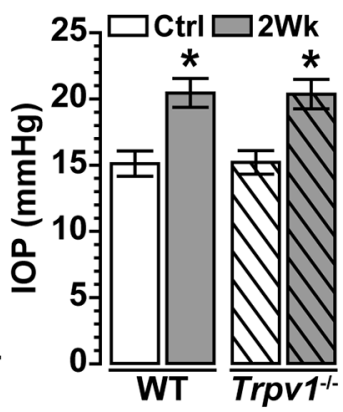

FIGURE 1 | Intraocular pressure (IOP) elevation in Trpv1-/- mice following microbead occlusion. (A) PCR product of wild type (WT) Trpv1 in C57 mice at 289 bp (lane 2-3) and mutant Trpv1 at 176 bp (lanes 4-5) compared to no-template control (NTC, lane 1). (B) A single unilateral injection of microbeads (1.5 $\mu$ I) elevates IOP for 2 Weeks in WT (+33\%) and Trpv1 ${ }^{-/-}(+36 \%)$ eyes compared to an equivalent volume saline injection (Ctrl; $\left.{ }^{*} p \leq 0.003\right)$. Post-injection IOP in each eye did not differ between strains $(p=0.99 ; n=18$ animals for each. Statistic: one-way ANOVA, Tukey post hoc (B). Data $=$ mean \pm SEM.

activity in the absence of light stimulation was highly variable and did not differ by genotype or IOP ( $p \geq 0.09$; Figure 3A). Elevated IOP had opposing effects on the response to light, increasing it for WT but diminishing it for $\operatorname{Trp} v 1^{-/-} \alpha \mathrm{ON}-\mathrm{S}$ RGCs (Figure 3B). When quantified, elevated IOP increased both the mean response to light for WT $(+45 \%)$ and the integrated response $(+42 \%)$, defined by the area under the curve for firing rate during the light stimulus ( $p \leq 0.04$; Figure $3 \mathrm{C}$ ). The enhanced response is consistent with our previous results (Risner et al., 2018). For Trpv1 ${ }^{-/-} \alpha$ ON-S RGCs, elevated IOP decreased the mean and integrated responses $(-38$ and $-36 \%$, respectively, $p \leq 0.05)$. Interestingly, the enhanced response for WT $\alpha \mathrm{ON}-\mathrm{S}$ cells was approximately equivalent to that of $\operatorname{Tr} p v 1^{-/-}$control cells, while the reduced response for $\operatorname{Tr} p v 1^{-/-}$cells after elevated IOP matched the WT control response $(p \geq 0.34)$. Elevated IOP further depolarized the RMP for WT $\alpha$ ON-S RGCs (+14\%, $p<0.001$; Figure 3D), again consistent with our previous finding (Risner et al., 2018), but not for $\operatorname{Trpv1} 1^{-/-}$cells. To determine if these differences remained in the absence of lightdriven presynaptic signaling, we current-clamped $\alpha \mathrm{ON}-\mathrm{S}$ RGCs using incremental $(20 \mathrm{pA})$ injections of depolarizing current to measure intrinsic responses through voltage-gated channels following previous work (Mitra and Miller, 2007). For both WT and Trp $v 1^{-/-} \alpha \mathrm{ON}-\mathrm{S}$ RGCs, direct depolarization-induced a corresponding increase in firing rate (Figure 3E). However, while elevated IOP enhanced this relationship for WT cells, causing a $33 \%$ increase in the mean $(p=0.01)$, we found a $33 \%$ decrease for $\operatorname{Tr} p v 1^{-/-}$cells $(p=0.002$; Figure $3 F)$. Thus, direct activation of voltage-gated channels by depolarizing current steps mirrored the major differences between the light responses of WT and Trpv1-/- $\alpha \mathrm{ON}-\mathrm{S}$ cells subjected to elevated IOP. Possible reasons for this effect are discussed below.

\section{Trpv1-/- Has the Opposite Influence on $\alpha$ OFF-Sustained RGC Excitability With Elevated IOP}

The mosaic of $\alpha$-Sustained RGCs contains complementary ON and OFF arrays for partitioning contrast information for use by the visual system (Liang and Freed, 2012). Thus, we identified $\alpha$ OFF-Sustained ( $\alpha$ OFF-S) RGCs using analogous criteria (Della Santina et al., 2013; Ou et al., 2016). Like their ON counterparts, WT $\alpha$ OFF-S RGCs have a large cell body with an expansive dendritic field that projects proximal to the complementary ChAT labeling in the OFF sublamina; they too express SMI-32 (Figure 4A). Light suppresses excitation in these cells, which respond with a sustained volley of action potentials at light offset (Figure 4B). The same cell type in $\operatorname{Trp} v 1^{-/-}$retina had similar morphology but appeared smaller (Figure 4C) with a less robust response to light offset (Figure 4D). When quantified, the $\operatorname{Tr} p v 1^{-/-} \alpha$ OFF-S RGC response was significantly less than WT (Figures 4E,F), with a 38\% smaller mean response to light offset $(p<0.001)$, though the peak response to light offset did not differ $(p=0.96)$. The RMP for $\alpha$ OFF-S RGCs from Trp $v 1^{-/-}$ retinas likewise was slightly more depolarized than WT $(p=0.07$; Figure 4F). As with $\alpha \mathrm{ON}-\mathrm{S}$ RGCs, pharmacological antagonism of TRPV1 with IRTX mimicked the major influence of $\operatorname{Trpv1} 1^{-/-}$ on the mean light response of $\alpha$ OFF-S RGCs, causing a decrease $(p<0.001$; Figures 4G,H).

Spontaneous activity in WT $\alpha$ OFF-S RGCs was higher than in $\alpha \mathrm{ON}-\mathrm{S}$ RGCs (see Figure 3A), consistent with their preference for darkness, and did not change with 2 weeks of elevated IOP $\left(p=0.31\right.$; Figure 5A). Interestingly, $\operatorname{Tr} p v 1^{-/-} \alpha$ OFF-S control RGCs had less spontaneous firing than WT $(p=0.025)$, but this increased with elevated IOP $(p=0.05)$. As expected from our previous work (Risner et al., 2018), elevated IOP enhanced the peak response to light offset for WT $\alpha$ OFF-S RGCs and depolarized the RMP ( $p \leq 0.04)$; the mean and integrated responses were modestly enhanced (Figures 5B-D). In contrast to $\alpha \mathrm{ON}-\mathrm{S}$ RGCs, elevated IOP also enhanced the response of Trp $v 1^{-/-} \alpha$ OFF-S RGCs, increasing both the mean $(+87 \%)$ and integrated $(+84 \%)$ response to light offset $(p \leq 0.05)$. Similar to $\alpha \mathrm{ON}-\mathrm{S}$ RGCs, the changes to Trp $v 1^{-/} \alpha \mathrm{OFF}-\mathrm{S}$ RGCs with elevated IOP effectively brought their response to levels of WT control cells $(p \geq 0.3)$. Like Trpv1 $1^{-/-} \alpha \mathrm{ON}-\mathrm{S}$ RGCs, elevated IOP did not change RMP in Trpv1-/- $\alpha$ OFF-S RGCs. Once again pulses of depolarizing currents increased the firing rate 

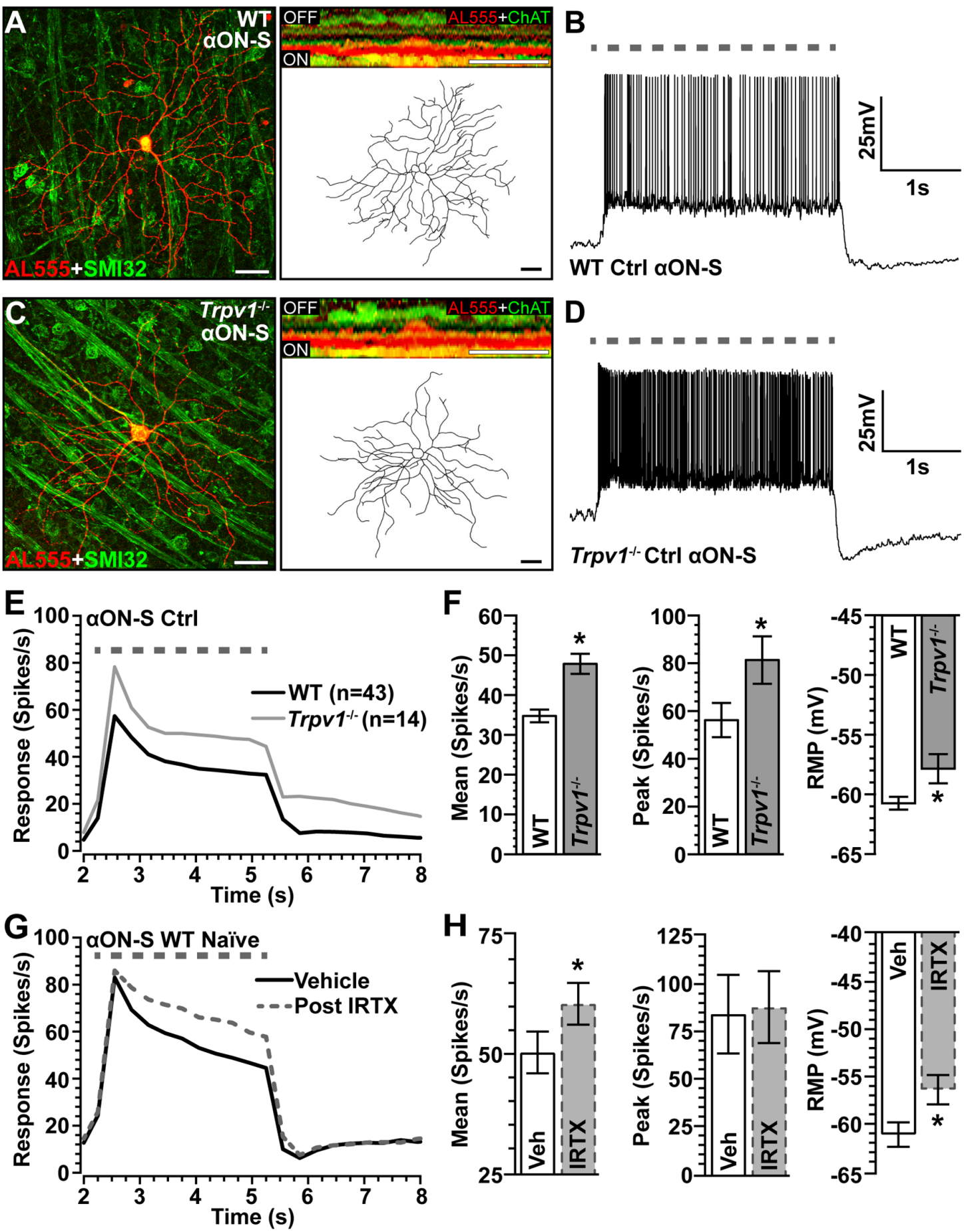

FIGURE 2 | Comparison of WT and Trpv1-/- $\alpha \mathrm{ON}$-sustained retinal ganglion cells (RGCS). (A) Confocal micrograph of WT $\alpha \mathrm{ON}$-S RGC following intracellular filling with Alexa555 dye (AL555) shows strong localization of non-phosphorylated neurofilament H (SMI32, green). Orthogonal rotation (inset) shows dendrites ramifying narrowly in the $\mathrm{ON}$ region of the inner plexiform layer (IPL) relative to the label for choline acetyltransferase (ChAT, green). (B) WT $\alpha \mathrm{ON}-\mathrm{S}$ RGC responds to light (365 nm, $3 \mathrm{~s}$; dashed line) with a sustained train of action potentials during whole-cell current-clamped conditions that preserved resting membrane potential (RMP; 0 pA). (C) Trpv1-1- $\alpha \mathrm{ON}-\mathrm{S}$ RGC has similar morphology and branching pattern and a more robust sustained response to light (D). When averaged across cells (E,F), the response of Trpv ${ }^{-1-} \alpha \mathrm{ON}-\mathrm{S}$ RGCs exceeded WT for both mean (53.4 $\pm 7.7 \mathrm{vs.} 35.5 \pm 4.8$ spikes/s; $\left.{ }^{*} p<0.001\right)$ and peak firing rate (81.4 \pm 9.9 vs. $56.2 \pm 7.2$ spikes/s; ${ }^{*} p=0.02$ ), with more depolarized (RMP; $-57.9 \pm 1.1 \mathrm{mV}$ vs. $-60.6 \pm 0.6 \mathrm{mV}$, $\left.{ }^{*} p=0.03\right)$. (G,H) For naïve WT $\alpha \mathrm{ON}-\mathrm{S}$ RGCs ( $n=7$ ), bath application of IRTX (100 nM) significantly increased the mean light response histogram $\left(+40 \% ;{ }^{*} p<0.001\right)$ and depolarized the RMP $\left({ }^{*} p=0.009\right)$. Peak response was unaffected $(p=0.77)$. WT control group contains 14 cells from naïve eyes and 29 cells from saline-injected eyes. $(\mathbf{A}, \mathbf{C})$ Scale bar $=40 \mu \mathrm{m}$. Statistics: Student's $t$-tests $(\mathbf{F})$, paired $t$-tests $\mathbf{( H )}$. Data $=$ mean \pm SEM. 

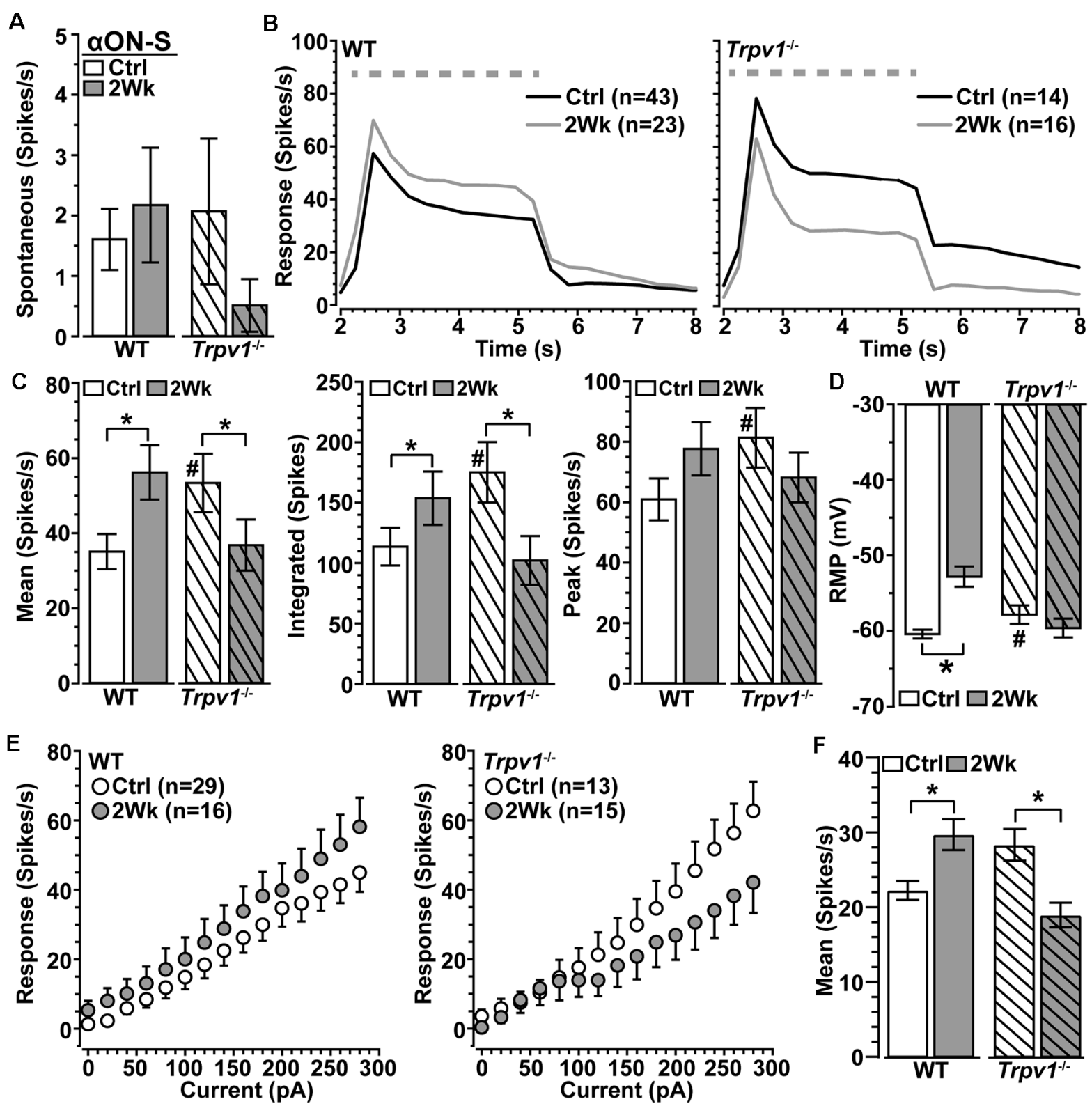

FIGURE 3 | Opposing influence of elevated IOP on WT vs. Trpv1 ${ }^{-/-} \alpha \mathrm{ON}-\mathrm{S}$ RGCs. (A) The spontaneous firing rate of WT and Trpv1 $1^{-/-} \alpha \mathrm{ON}-\mathrm{S}$ RGCs is not affected by elevated IOP $(p \geq 0.07)$. (B) Response to light (dashed line) increases for WT $\alpha$ ON-S RGCs with elevated IOP but decreases for Trpv1-/-. (C) Elevated IOP increased the mean and integrated light response for WT $\alpha \mathrm{ON}-\mathrm{S}$ RGCs ( $\left.{ }^{*} p \leq 0.04\right)$, but decreased both for Trpv1 ${ }^{-/-}\left({ }^{*} p \leq 0.05\right)$. The integrated response for Trpv1-/- Ctrl cells exceeded that for WT (\# $p=0.05$ ), as did mean and peak (\#, see Figure 2). (D) RMP for WT $\alpha \mathrm{ON}-\mathrm{S}$ RGCS becomes more depolarized with elevated IOP ( $-53 \pm 1.4$ vs. $-60.6 \pm 0.5 \mathrm{mV}$; $\left.{ }^{*} p<0.001\right)$; for control, Trpv1-/- was more depolarized (\#, see Figure 2). (E) The voltage response of WT and Trpv1-1- $\alpha$ ON-S RGCs following brief (1 s) pulses of depolarizing current (0-280 pA; 2 s inter-stimulus interval). (F) Elevated IOP significantly increased voltage response averaged across current pulses for WT $\alpha$ ON-S RGCs $\left({ }^{*} p=0.01\right)$ but decreased it for Trpv1 ${ }^{-1-}$ compared to Ctrl $\left({ }^{*} p=0.002\right)$. Statistics: Mann-Whitney test (A), Student's t-tests (C,D), Kruskal-Wallis test, Dunn's post hoc (F). Data = mean \pm SEM.

for all $\alpha$ OFF-S RGCs, though the responses reached a plateau (Figure 5E). Elevated IOP enhanced the mean of currentinduced excitability for both WT $(+28 \%)$ and $\operatorname{Trpv} 1^{-/-}(+25 \%)$ $\alpha$ OFF-S RGCs compared to their controls ( $p \leq 0.002$; Figure $5 F$ ). Thus, as it did for $\alpha \mathrm{ON}-\mathrm{S}$ RGCs, direct activation of voltagegated channels by depolarizing current steps mirrored the major differences between the light responses of WT and Trpv1 $1^{-/-}$ $\alpha \mathrm{OFF}-\mathrm{S}$ RGCs.

Our results demonstrate that while elevated IOP enhances excitability in WT $\alpha \mathrm{ON}-\mathrm{S}$ and $\alpha$ OFF-S RGCs, it has an opposing influence on the same cell types in $\operatorname{Tr} p v 1^{-/-}$retina: decreasing excitability for $\alpha \mathrm{ON}-\mathrm{S}$ RGCs while increasing it for $\alpha \mathrm{OFF}-\mathrm{S}$ cells. 

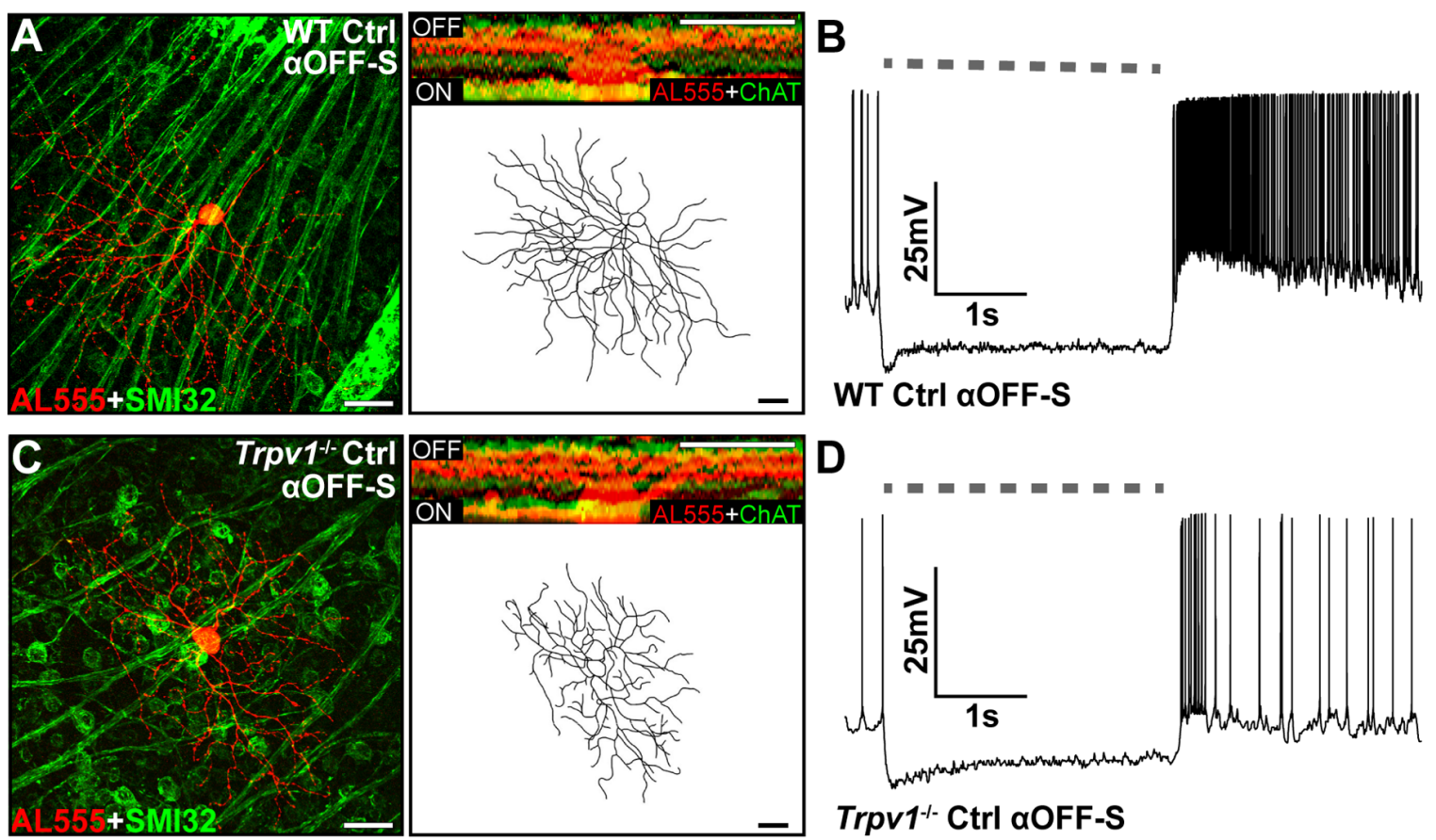

WT Ctrl aOFF-S
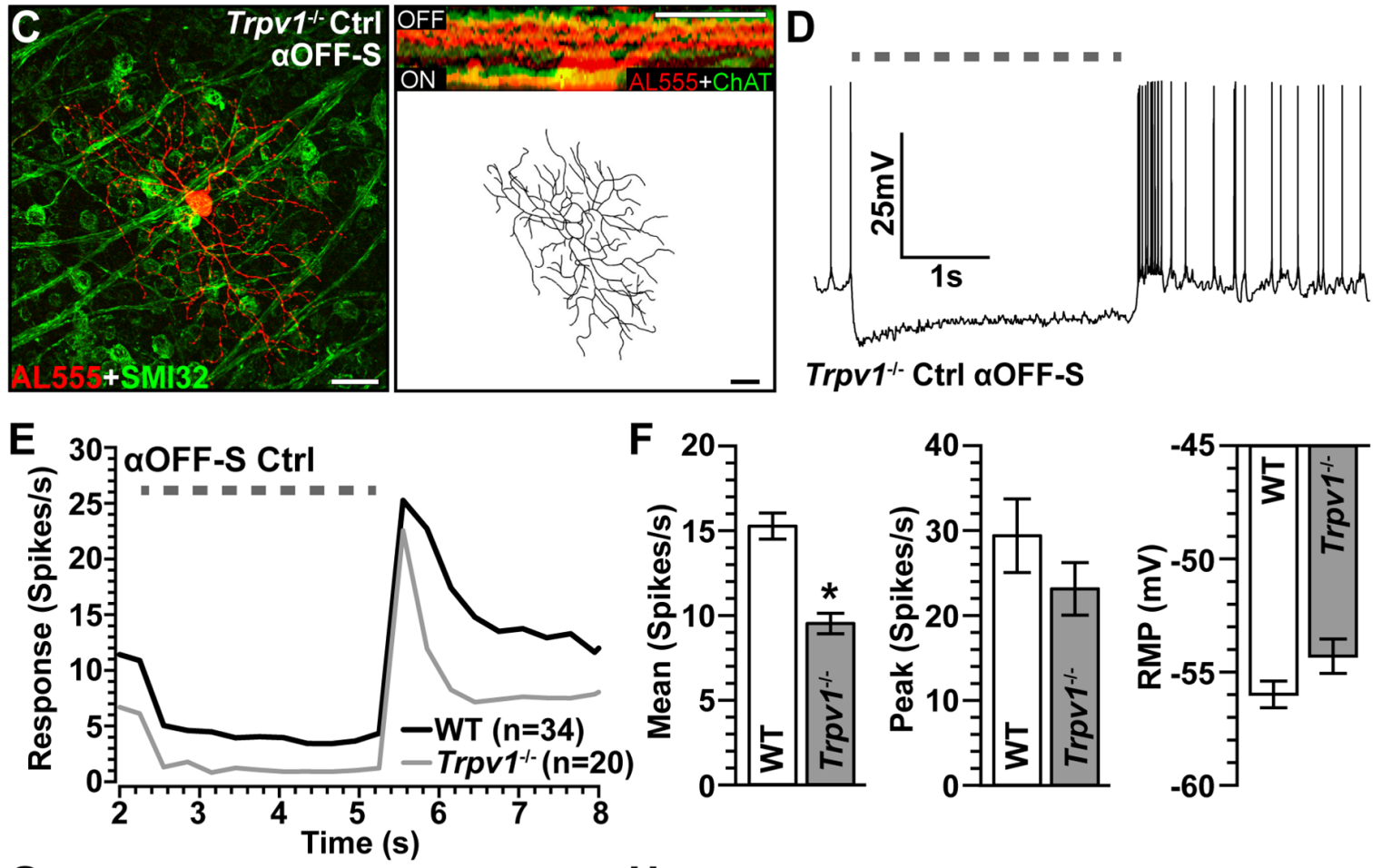

G
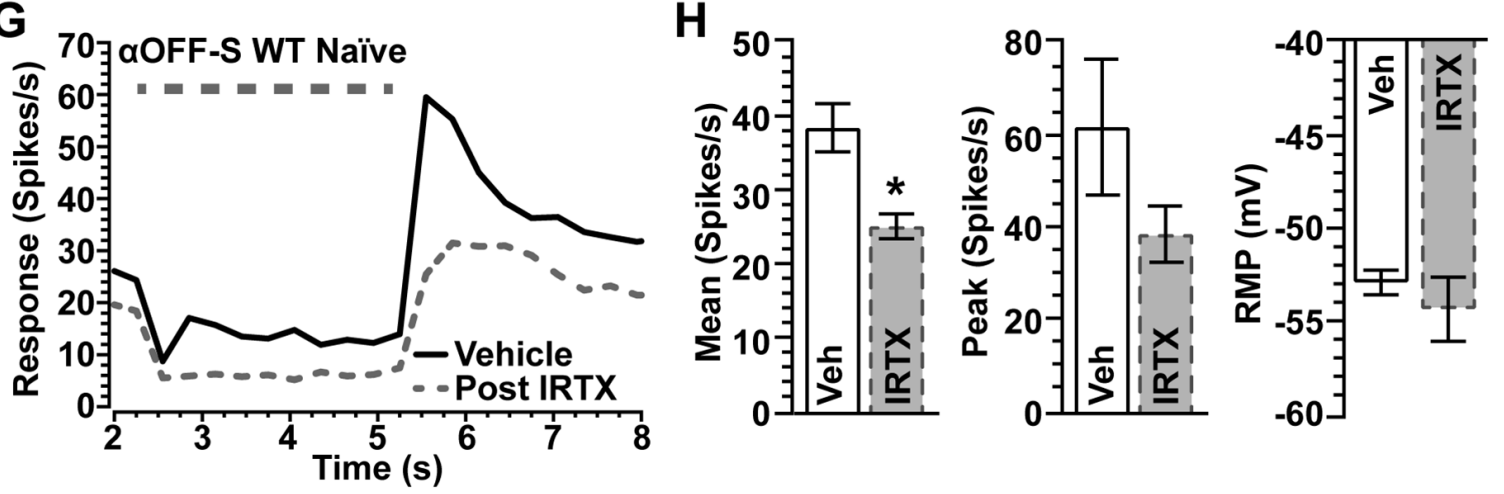

FIGURE 4 | Comparison of WT and Trpv1-1- $\alpha$ OFF-sustained RGCs. (A) WT $\alpha$ OFF-S RGC following intracellular filling (AL555) and labeled for SMI-32 shows dendrites ramifying narrowly in the OFF region of the IPL proximal to ChAT labeling (inset). (B) The voltage response of WT $\alpha$ OFF-S RGC increases and is sustained at the light offset, while excitation diminishes during light stimulation (dashed line). (C) Trpv1 ${ }^{-1}-\alpha$ OFF-S RGC has similar morphology and response to light offset,

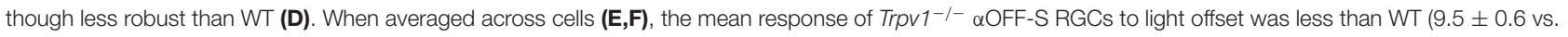
$15.3 \pm 0.8$ spikes $\left./ \mathrm{s} ;{ }^{*} p<0.001\right)$, though the RMP was slightly more depolarized ( $-54.3 \pm 0.8$ vs. $\left.-56.0 \pm 0.6 \mathrm{mV} ; p=0.07\right)$. (G,H) For WT $\alpha$ OFF-S RGCs $(n=5)$, bath application of IRTX (100 nM) reduced the mean response histogram to light offset ( $\left.-34 \% ;{ }^{*} p<0.001\right)$, though peak off response and RMP were not affected $(p \geq 0.14)$. WT control group consists of 10 cells from naive eyes and 24 cells from saline-injected eyes. (A,C) Scale $=40 \mu \mathrm{m}$. Statistics: Mann-Whitney tests (F) and paired $t$-tests $\mathbf{( H )}$. Data $=$ mean \pm SEM. 

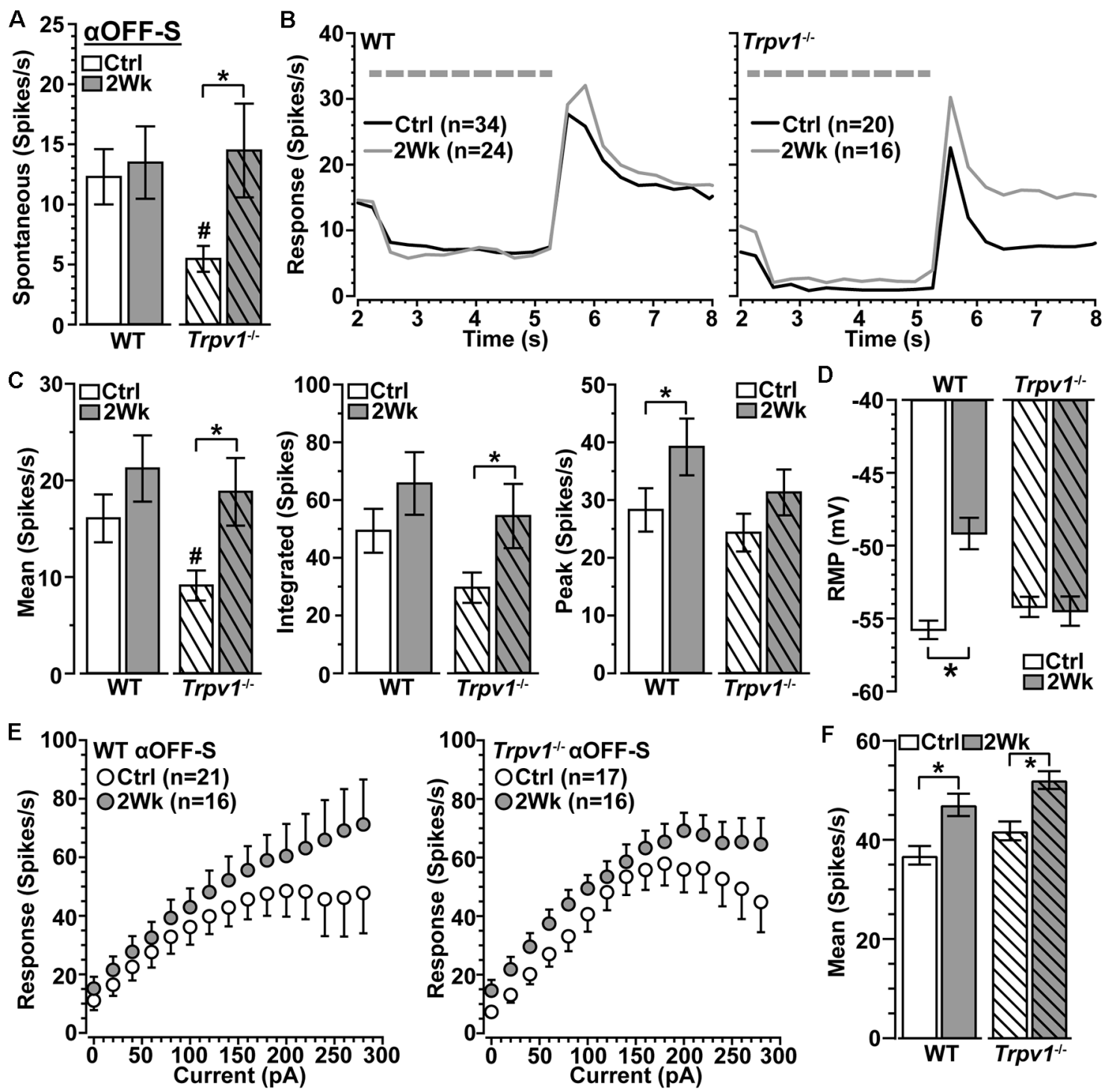

FIGURE 5 | Elevated IOP similarly influences WT and Trpv1 ${ }^{-1-} \alpha$ OFF-S RGCs. (A) Spontaneous spike activity of Trpv1 ${ }^{-/-} \alpha$ OFF-S RGCs is significantly less than WT for control cells $\left({ }^{\#} p=0.025\right)$ but increased with elevated IOP ( $\left.{ }^{*} p=0.022\right)$. (B,C) Response to light offset increases for both WT and Trpv $1^{-/-} \alpha \mathrm{OFF}-\mathrm{S}$ RGCs, including peak response for WT ( $\left.{ }^{*} p=0.05\right)$ and mean and integrated response for Trpv $1^{-1-}\left({ }^{*} p \leq 0.05\right)$; the mean response for Trpv $1^{-1-}$ control cells was less than WT (\#, see Figure 4). (D) Elevated IOP depolarized RMP for WT ( ${ }^{*} p \leq 0.001$ ) but not Trpv1-1- $\alpha$ OFF-S cells $(p=0.81)$. (E) The voltage response of WT and Trpv1 $1^{-1-} \alpha$ OFF-S RGCs following brief (1 s) pulses of depolarizing current (O-280 pA; $2 \mathrm{~s}$ inter-stimulus interval). (F) Elevated IOP significantly increased response averaged across current pulses for both genotypes compared to respective control cells ( $\left.{ }^{*} p \leq 0.002\right)$, which did not differ by genotype $(p=0.21)$. Statistics: Student's $t$-tests $(\mathbf{A}, \mathbf{D})$, Student's $t$-tests (peak response) or Mann-Whitney tests (mean and integrated responses, C), Kruskal-Wallis, Dunn's post hoc (F). Data presented as mean \pm SEM.

These induced changes bring the response of each to that of the corresponding WT control cell.

\section{An Axogenic Component of TRPV1's Physiological Influence}

Glutamate released from bipolar cell axon terminals conveys light-induced excitation through ionotropic receptors (primarily AMPA-sensitive) localized to postsynaptic sites within RGC dendrites (Wässle, 2004; Euler et al., 2014). Upon binding glutamate, excitation through these receptors enables activation of $\mathrm{NaV}$ channels to propagate depolarization in the RGC (Kalbaugh et al., 2009; Sullivan and Miller, 2012). In the retina, $\mathrm{NaV}$ subunits localize predominately to RGCs and their axons (Caldwell et al., 2000; Boiko et al., 2003; Werginz et al., 2020), including the $\mathrm{Na}_{\mathrm{V}} 1.6$ subunit that initiates and facilitates the propagation of action potentials and contributes to enhanced excitability (Rush et al., 2005; Hu et al., 2009; Risner et al., 2018). Our results here show that injections of depolarizing current to activate $\mathrm{NaV}$ in the absence of conventional lightinduced presynaptic excitation captured the major differences 
in the light-evoked spike rate of WT and $\operatorname{Trpv1} 1^{-1-} \alpha \mathrm{ON}-\mathrm{S}$ and $\alpha$ OFF-S RGCs exposed to elevated IOP (Figures 3F, 5F). Next, we conducted the converse experiment to isolate the contribution of conventional excitatory currents to the light response.

We voltage-clamped WT and Trpv1-/- RGCs near the reversal potential of $\mathrm{Cl}^{-}(-65 \mathrm{mV})$ and applied tetrodotoxin (TTX, $1 \mu \mathrm{M}$ ) to prevent activation of $\mathrm{NaV}$ channels (Pang et al., 2003). Under these conditions, light-induced a transient peak in inward current followed by a sustained component for $\alpha \mathrm{ON}-\mathrm{S}$ RGCs (Figure 6A). For control cells from each genotype, the peak inward current did not differ, and elevated IOP had only a modest effect ( $p=0.31$; Figure 6B, left). The area of the lightevoked inward current also did not change with IOP or differ between WT and $\operatorname{Tr} p v 1^{-/-}(p=0.88$; Figure 6B, right). For WT and Trp $v 1^{-1-} \alpha$ OFF-S RGCs, light-induced a persistent outward current, while offset elicited a transient inward peak current followed by repolarization (Figure 6C). While repolarization appeared quicker for $\operatorname{Tr} p v 1^{-1-} \alpha$ OFF-S RGCs, the peak inward current at light offset was similar to WT for control cells $(p>0.99)$; elevated IOP had no effect on peak current for either WT or Trpv1 $1^{-/} \alpha$ OFF-S cells ( $p=0.42$; Figure $6 \mathrm{D}$, left). For control $\alpha$ OFF-S RGCs, Trpv1 $1^{-/-}$reduced the area of the lightevoked inward current, but overall, neither genotype nor IOP elevation affected the area of the inward current $(p=0.35$; Figure 6D, right). Thus, silencing $\mathrm{NaV}$ channels and isolating retinal excitatory signaling eradicated both the differences in light-evoked activity between WT and $\operatorname{Trpv1} 1^{-/-}$RGCs and the changes in response due to elevated IOP.

\section{Trpv1-/- RGC Dendritic Arbors Are Less Susceptible to Pruning}

Since Trpv1 $1^{-/-}$accelerates axon degeneration with elevated IOP (Ward et al., 2014), we asked whether dendritic arbors are similarly susceptible. Two weeks of elevated IOP appeared to reduce branching for WT $\alpha \mathrm{ON}-\mathrm{S}$ RGCs with little or no effect on Trpv1 $1^{-/}$cells, which were more compact (Figure 7A), as noted earlier (Figure 2). Indeed $\operatorname{Trpv1^{-1-}} \alpha \mathrm{ON}-\mathrm{S}$ RGCs from control retina had smaller cross-sectional areas than WT $(p=0.045)$ and less total dendritic length $(p=0.002$; Figure 7B). Though dendritic arbors for Trpv1 $1^{-/-} \alpha \mathrm{ON}-\mathrm{S}$ RGCs were only $12 \%$ smaller in area than WT $(p=0.34)$, they were significantly less complex at a given distance from the soma (Figure 7C). The mean number of branch points per dendritic arbor did not differ from WT $(p=0.12)$. Elevated IOP reduced dendritic branch points for WT $(p=0.03)$ but not Trpv1 $1^{-1-} \alpha \mathrm{ON}-\mathrm{S}$ RGCs (Figure 7D). This brief period of elevation did not affect dendritic field area, total dendritic length, or the number of primary dendrites for either WT $(p \geq 0.13)$ or Trpv1 $1^{-/-} \alpha \mathrm{ON}-\mathrm{S}$ RGCs $(p \geq 0.66)$. We found similar results for $\alpha$ OFF-S RGCs. For Trpv1 $1^{-1-}$ retinas, these cells were more compact (Figure 7E), with significantly less total dendritic length and complexity (Figures 7F,G). Once again, elevated IOP reduced the number of branch points in WT but not Trpv1 $1^{-/}$aOFF-S RGCs $(p=0.03$; Figure $7 \mathbf{H}$ ), without affecting field area, length, or primary dendrites for either WT $(p \geq 0.14)$ or Trpv1 $1^{-1-} \alpha$ OFF-S RGCs $(p \geq 0.45)$. Thus, $\alpha$-Sustained RGCs from Trpv1 $1^{-1-}$ retinas are more compact than WT but less susceptible to IOP-related pruning.

\section{DISCUSSION}

\section{Influence of Trpv1-/- on RGC Excitability}

Our fundamental finding is that in the absence of induced stress, Trpv1 $1^{-/-}$increases the light-driven excitability of $\alpha \mathrm{ON}-\mathrm{S}$ RGCs while decreasing the excitability of $\alpha$ OFF-S RGCs (Figures 2, 4). Some $20-40 \%$ of all RGCs express TRPV1, as shown with $\mathrm{Trpv1}^{\mathrm{Cre}}: \mathrm{Ai} 9$ and $\operatorname{Trpv1}^{\mathrm{Cre}}: \mathrm{AAV}^{\text {-Flex-tdTomato }}$ reporter mice (Jo et al., 2017), and about $36 \%$ of SMI-32+ $\alpha$ RGCs localize TRPV1, which likely includes $\alpha$ RGCs presented here (Lakk et al., 2018; Figures 2, 4). Retinal horizontal cells also apparently contain TRPV1 (Bouskila et al., 2020). These data are consistent with published accounts of TRPV1 localization in both RGCs and other components of their presynaptic circuitry (Sappington et al., 2009, 2015; Weitlauf et al., 2014). Even so, our data suggest that TRPV1 activation also mediates RGC-intrinsic mechanisms. The polarity of the changes in light response of Trpv1 ${ }^{-1-}$ RGCs under control conditions can be reproduced by driving membrane potential directly, through injection of depolarizing currents that largely bypass conventional synaptic activity (Figures 3E,F, 5E,F). Additionally, blocking $\mathrm{NaV}$ channels and isolating retinal excitatory inputs abolished the differences in light-evoked activity between WT and Trpv1-/control $\alpha \mathrm{ON}-\mathrm{S}$ and $\alpha \mathrm{OFF}-\mathrm{S}$ RGCs (Figure 6). Thus, while the differential effect of Trpv1-/- on $\alpha \mathrm{ON}-\mathrm{S}$ and $\alpha \mathrm{OFF}-\mathrm{S}$ RGC excitability may reflect differences in TRPV1 expression in either the RGCs or their presynaptic circuits, our results suggest that TRPV1 activation comprises an intrinsic voltagedependent component.

The impact of $\operatorname{Trpv1} 1^{-/-}$on RGC excitability does not seem to be due to some sort of developmental compensation to change retinal circuitry. This is supported by our finding that antagonism of TRPV1 by IRTX in naïve WT retinas reproduce the changes in light-evoked mean spike rate that we also observed in Trpv1 $1^{-1-} \alpha \mathrm{ON}-\mathrm{S}$ and $\alpha \mathrm{OFF}-\mathrm{S}$ RGCs (Figures $2 \mathrm{E}-\mathrm{H}, 4 \mathrm{E}-\mathrm{H}$ ). However, we also found Trpv1 $1^{-/-}$reduces soma area, dendritic length, and complexity of $\alpha \mathrm{ON}-\mathrm{S}$ and $\alpha \mathrm{OFF}-\mathrm{S}$ RGCs (Figure 7). Since smaller cells have higher input resistance that requires smaller currents to elicit repetitive spiking, RGCs from Trpv1-/retina may be intrinsically more excitable (Kernell, 1966). This possibility is not fully supported by our data. $\operatorname{Trp} v 1^{-1-}$ does not significantly affect the spontaneous firing rate of $\alpha \mathrm{ON}-\mathrm{S}$ cells (Figure 3A), and responses to small test potentials are similar (Figure 3E). Moreover, Trpv1 $1^{-/} \alpha$ OFF-S RGCs are smaller yet spontaneous activity is reduced (Figure 5A), and responses to low test potentials are like WT control $\alpha$ OFF-S cells (Figure 5E).

Although we found TRPV1 antagonism and Trpv1 ${ }^{-1-}$ similarly drive light-evoked mean firing in $\alpha \mathrm{ON}-\mathrm{S}$ and $\alpha \mathrm{OFF}-\mathrm{S}$ cells (Figures 2G,H, 4G,H), Trpv1 $1^{-1-}$ also enhanced peak firing rate of $\alpha \mathrm{ON}-\mathrm{S}$ RGCs; IRTX did not reproduce this change (Figures 2G,H). Since peak firing rate reflects the voltage-gated capacity of a cell, $\operatorname{Trpv1^{-1-}}$ may induce a compensatory increase in $\mathrm{NaV}$ channels that enhances 

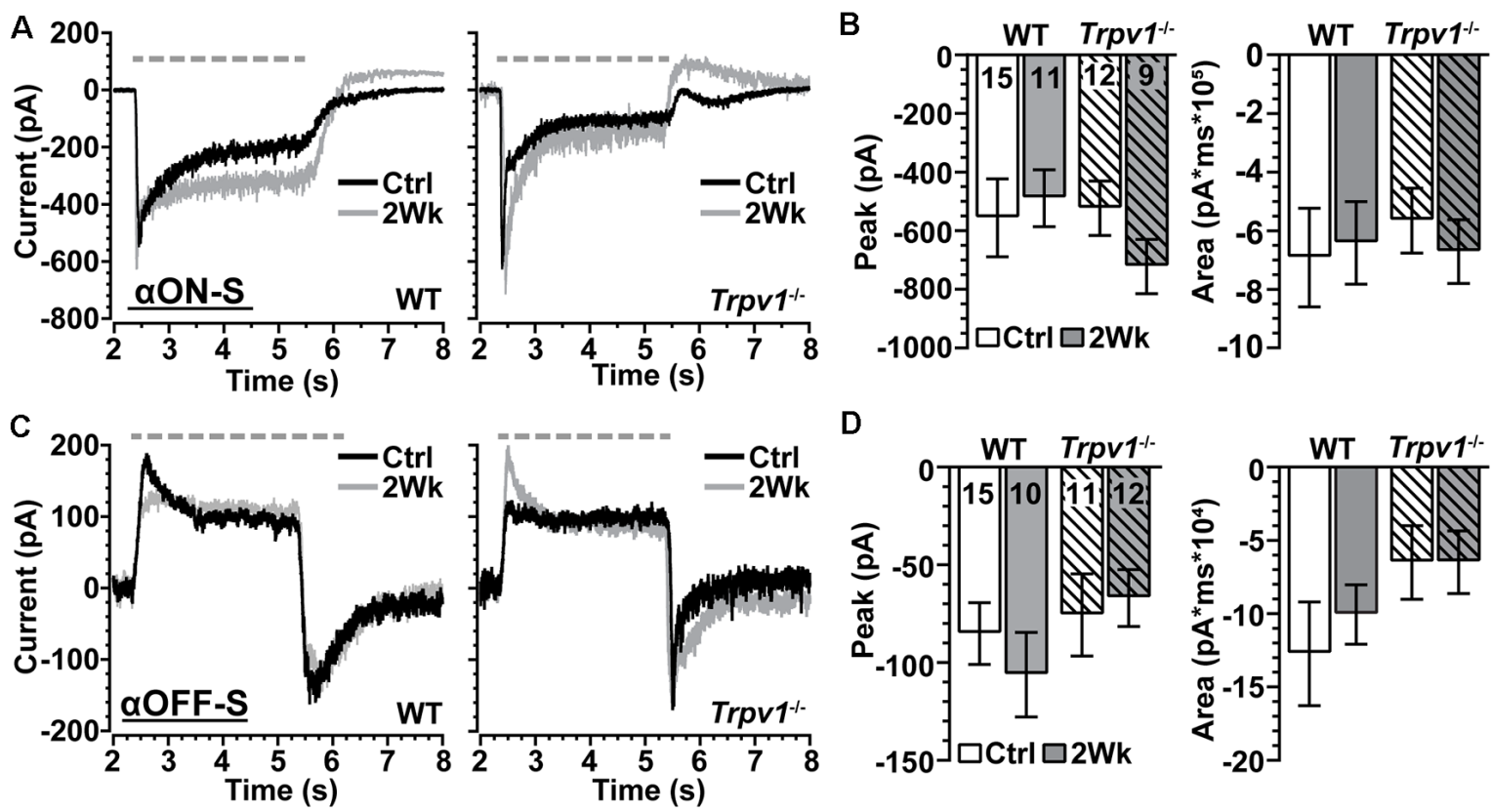

D
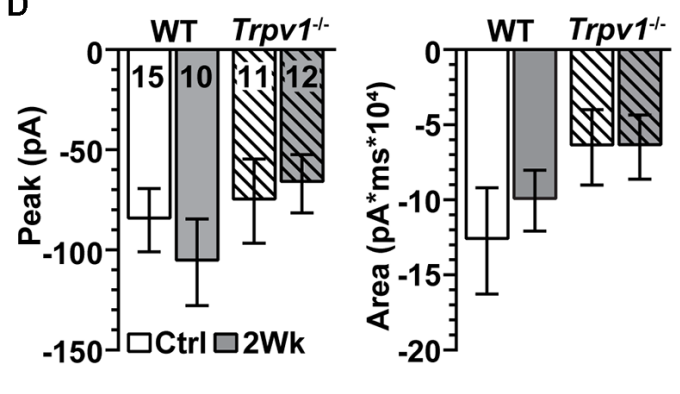

FIGURE 6 | Trpv1-/- does not significantly influence excitatory synaptic mechanisms. (A) Light-evoked currents (voltage-clamp at -65 mV) of WT and Trpv1-/Ctrl and 2 Week $\alpha$ ON-S RGCs following application of tetrodotoxin (TTX, $1 \mu \mathrm{M})$. Elevated IOP did not affect the peak (B, left) or area of the inward current (B, right) for either WT or Trpv1-1- 2 Week RGCs compared to their respective Ctrl cells, which also did not differ between WT and Trpv1-/- $(p \geq 0.31)$. (C) For $\alpha$ OFF-S RGCs, light offset elicited a transient inward peak followed by a slower recovery. Elevated IOP did not affect the peak (D, left) or area (D, right) of the inward current for either WT or Trpv1-1- 2 Week RGCs compared to their respective Ctrl cells, which did not differ between WT and Trpv1-/- $(p \geq 0.35)$. Statistics: Kruskal-Wallis tests, Dunn's post hoc tests (B,D). Data $=$ mean \pm SEM.

peak spike rate. If so, enhancement of the peak firing rate through $\mathrm{NaV}$ channel plasticity likely would require long-term administration of a TRPV1 antagonist. In support of this idea, we have previously found evidence of enhanced localization of $\mathrm{Na}_{\mathrm{V}} 1.6$ in $\operatorname{Trp} v 1^{-/-}$optic nerve axons (McGrady et al., 2020).

In hippocampal neurons, TRPV1 activation triggers long-term depression, which is reduced by $\operatorname{Tr} p v 1^{-/-}$(Gibson et al., 2008). Similarly, we find $\operatorname{Tr} p v 1^{-/-}$increases excitability and depolarizes RMP of control $\alpha \mathrm{ON}-\mathrm{S}$ (Figures 2E,F). Interestingly, $\operatorname{Tr} p v 1^{-/-}$reduces light-driven excitability and modestly depolarizes RMP of control aOFF-S RGCs (Figures 4E,F). On the surface, these findings seem paradoxical. However, $\alpha \mathrm{OFF}$ RGCs, unlike $\alpha \mathrm{ON}$ cells, express low voltage-activated (LVA) $\mathrm{Ca}^{2+}$ channels (Margolis and Detwiler, 2007; Margolis et al., 2010). LVA Ca ${ }^{2+}$ channels require hyperpolarization to de-inactivate, rapidly activate to a depolarizing event, and quickly inactivate at low potentials (Margolis et al., 2010). Since Trpv1-/- $\alpha$ OFF-S RGCs are intrinsically more depolarized (Figure $4 \mathbf{F}$ ), the hyperpolarization during light onset may not be strong enough to de-inactivate LVA $\mathrm{Ca}^{2+}$ channels, reducing spike output at light offset. When excitability of $\operatorname{Trp} v 1^{-/-}$ control $\alpha$ OFF-S RGCs was measured by depolarizing current injections, spike rate was indistinguishable from WT (Figures 5E,F). These results suggest TRPV1 activity influences multiple voltage-sensitive mechanisms that control
RMP and excitability (Khomula et al., 2013; Cazade et al., 2017; McGrady et al., 2020).

\section{Influence of Trpv1-/- on RGC Excitability During Glaucoma}

Previously, we found an axogenic mechanism involving increased $\mathrm{Na}_{V} 1.6$ channels boosts membrane excitability and light responses of $\alpha \mathrm{ON}-\mathrm{S}$ and $\alpha \mathrm{OFF}-\mathrm{S}$ cells following 2 weeks of elevated IOP (Risner et al., 2018). Once again, we find elevated light responses and increased depolarization of the RMP for WT RGCs following 2 weeks of IOP elevation (Figures 3B-D, 5B-D). With elevated IOP, the $\operatorname{Tr} p v 1^{-/-} \alpha \mathrm{ON}-\mathrm{S}$ response to light decreased to the level of WT $\alpha \mathrm{ON}-\mathrm{S}$ RGCs from control retinas (Figures 3B-D), while the $\operatorname{Tr} p v 1^{-/-} \alpha \mathrm{OFF}-\mathrm{S}$ response to light offset increased to the corresponding WT control response (Figures 5B-D). The polarity of the changes in light response with elevated IOP is mirrored by directly activating voltagegated channels, through injection of depolarizing currents that largely avoid stimulating presynaptic activity (Figures 3E,F, 5E,F). Conversely, blocking $\mathrm{NaV}$ channels with TTX and voltage-clamping RGCs to reveal excitatory postsynaptic currents eradicated differences in light-evoked activity caused by IOP elevation for WT and Trpv1-/- $\alpha \mathrm{ON}-\mathrm{S}$ and $\alpha \mathrm{OFF}-\mathrm{S}$ RGCs (Figure 6).

Earlier, we found the net influence of activation of TRPV1 on excitation of RGCs reverses following 2 weeks of elevated IOP, from reducing excitation to increasing; the effect is 


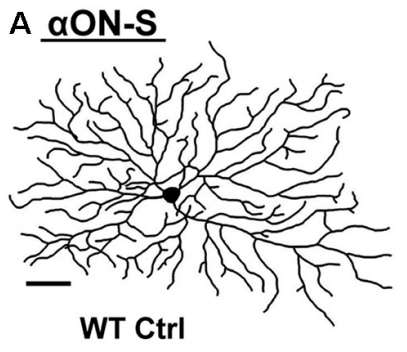

B
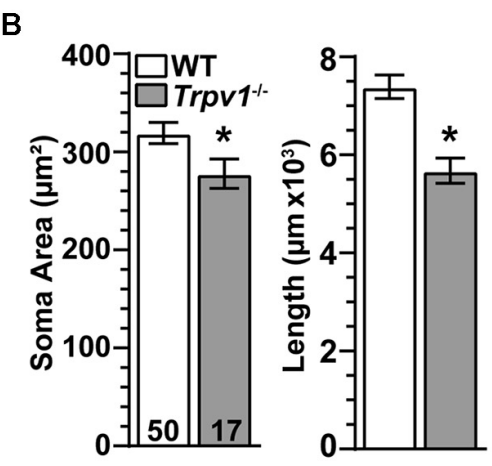

E aOFF-S

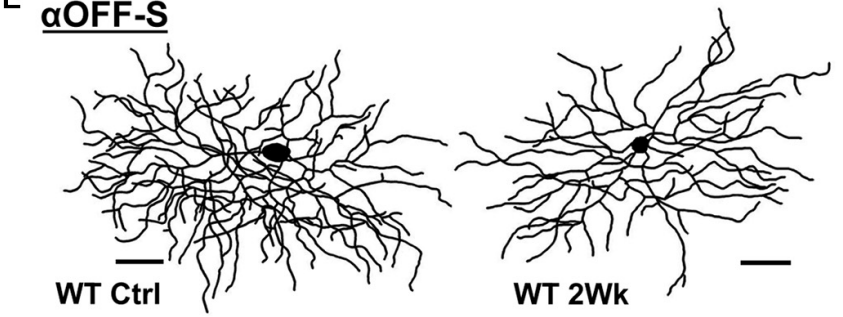

C

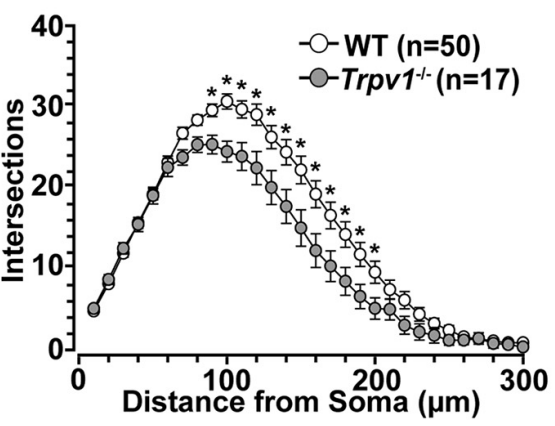

Trpv1\% Ctr

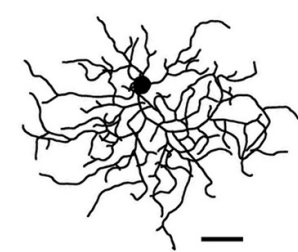

$\operatorname{Trpv1} 1^{-1-2 W k}$
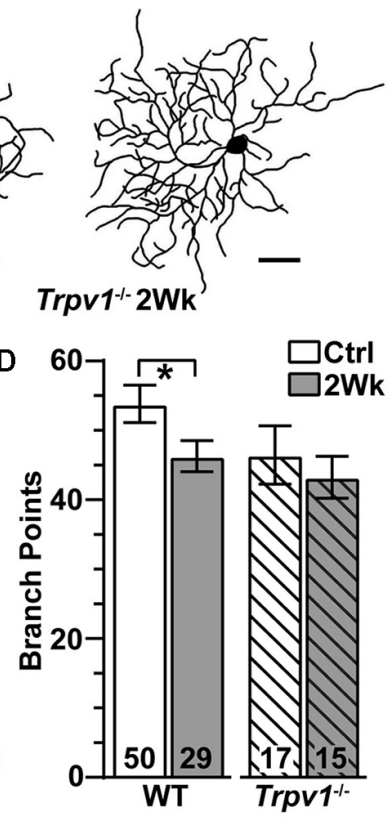

$\mathrm{F}$

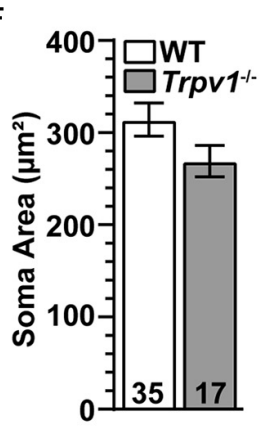

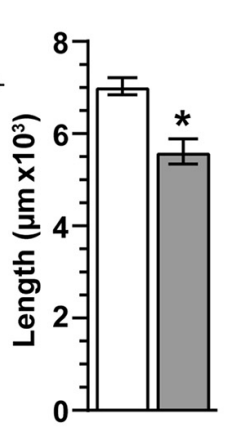

G

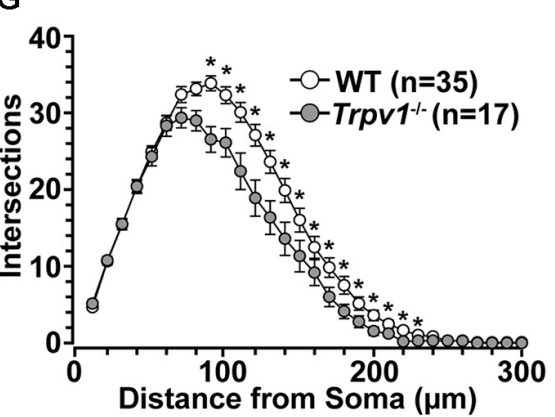

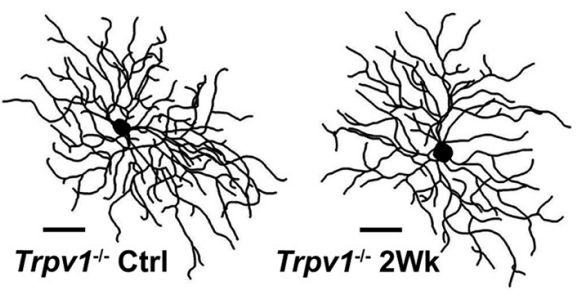

H 75

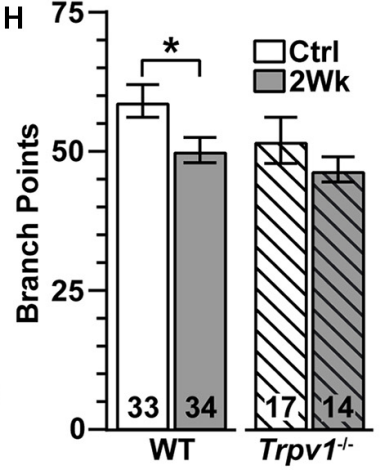

FIGURE 7 | Trpv1 1-/- RGCs are less susceptible to pruning. (A) Skeletonized dendritic arbors of $\alpha \mathrm{ON}-\mathrm{S}$ RGCs from Trpv1 ${ }^{-1-}$ retinas are more compact than WT, which lost branching following 2 weeks of elevated IOP. (B) Compared to WT, the mean soma area was smaller $\left({ }^{*} p=0.03\right)$ and total dendrite length less ( $\left.{ }^{*} p=0.002\right)$ for Trpv $1^{-1-}$ control $\alpha$ ON-S RGCs. (C) Averaged Sholl analysis for Trpv1-/- control $\alpha \mathrm{ON}-\mathrm{S}$ RGCs shows reduced dendritic complexity between $90-200 \mu \mathrm{m}$ from the soma compared to WT ( $\left.{ }^{*} p \leq 0.01\right)$. (D) Two weeks of elevated IOP reduced the mean number of branch points for WT ( $p=0.03$ ) but not Trpv1-/- $\alpha$ ON-S RGCs $(p=0.68)$. (E) Dendritic arbors for Trpv $1^{-1-} \alpha$ OFF-S RGCs are more compact than WT. (F) Compared to WT, total dendrite length was less for Trpv1-/- control $\alpha$ OFF-S RGCs ( $\left.{ }^{*} p<0.001\right)$. (G) Sholl analysis for Trpv1-/- control $\alpha$ OFF-S RGCs demonstrates reduced dendritic complexity from 90 to $230 \mu m$ from the soma $\left({ }^{*} p \leq 0.05\right)$. (H) Elevated IOP again reduced number of dendritic branch points for WT $\alpha$ OFF-S RGCs $(p=0.03)$ but not for Trpv1-/- $(p=0.48)$. (A,E) Scale $=50$ $\mu \mathrm{m}$. Statistics: Mann-Whitney tests (soma area, B,F) and Student's t-tests (B,D,F,H), Two-Way Repeated Measures ANOVA on Ranks, Dunn's post hoc (C,G).

transient, disappearing by 4 weeks of elevation (Weitlauf et al., 2014). Like its influence on excitability, increased TRPV1 expression in RGCs with elevated IOP is also transient (1-3 weeks; Weitlauf et al., 2014). The reversal in TRPV1's net influence on excitability with elevated IOP could help explain the opposing effects of $\operatorname{Tr} p v 1^{-/-}$on $\alpha$ RGCs. Following elevated IOP, RMP did not depolarize $\operatorname{Tr} p v 1^{-/-} \alpha$ RGCs as it did for WT (Figures 3D, 5D), possibly explaining the higher threshold of depolarization necessary to generate action potentials (Weitlauf et al., 2014). Without TRPV1's net excitatory 
influence, $\operatorname{Trp} v 1^{-/-} \alpha \mathrm{ON}-\mathrm{S}$ RGCs demonstrated a lesser response (Figure 3). Following 2 weeks of elevated IOP, despite the absence of TRPV1's excitatory influence, the $\operatorname{Trp} v 1^{-/-}$ $\alpha$ OFF-S RGC response to light offset increased (Figure 5), just like the response of WT RGCs. This enhanced excitability could be due to differences in $\mathrm{Na}_{\mathrm{V}} 1.6$ expression in Trpv1-/- ON and OFF RGC axon initial segments, just as $\mathrm{Na}_{V} 1.6$ differs between WT and Trpv1 $1^{-/-}$myelinated axons (McGrady et al., 2020).

Similar to our original report of enhanced excitability (Risner et al., 2018), here we found 2 weeks of IOP elevation reduced the number of dendritic branch points of WT $\alpha \mathrm{ON}-\mathrm{S}$ and $\alpha$ OFF-S RGCs (Figures 7D,H). Surprisingly, IOP elevation did not diminish the dendritic arborization of $\operatorname{Trp} v 1^{-/-}$RGCs as it did for WT (Figures 7D,H). This finding is perhaps unexpected, given the accelerating influence of $\operatorname{Trpv} 1^{-/-}$on RGC axon degeneration (Ward et al., 2014). However, TRPV1 activation induces rapid disassembly of dynamic microtubules (Goswami et al., 2006; Weitlauf et al., 2014). With elevated IOP, RGC dendritic arbors demonstrate a certain degree of remodeling as pruning progresses (El-Danaf and Huberman, 2015; Risner et al., 2018), presumably requiring microtubule reorganization and the high degree of energy it requires. With $\operatorname{Trp} v 1^{-/-}$, this process may be hindered, in effect slowing dendritic pruning by preventing the expense of remodeling. The opposing effects of $\operatorname{Trpv} 1^{-/-}$support the idea that axonal and dendritic degeneration is to some extent independent (Calkins, 2012).

We have suggested that enhanced excitability with elevated IOP may boost RGC signaling to the brain early in glaucoma progression to slow degeneration of RGC axons (Risner et al., 2018). However, Trpv1-/- RGCs ultimately fail in this effort, since elevated IOP equalizes the responses of $\alpha \mathrm{ON}-\mathrm{S}$ and $\alpha \mathrm{OFF}-$ S RGCs to those of WT control, and $\operatorname{Trp} v 1^{-/-}$accelerates optic nerve degeneration with elevated IOP (Ward et al., 2014). Even so, enhanced excitability is transient, and RGC axons in WT mice eventually degenerate with sustained IOP elevation. Since the optic nerve is metabolically stressed in glaucoma (Baltan et al., 2010; Calkins, 2012; Coughlin et al.,

\section{REFERENCES}

Baden, T., Berens, P., Franke, K., Román Rosón, M., Bethge, M., and Euler, T. (2016). The functional diversity of retinal ganglion cells in the mouse. Nature 529, 345-350. doi: 10.1038/nature 16468

Baltan, S., Inman, D. M., Danilov, C. A., Morrison, R. S., Calkins, D. J., and Horner, P. J. (2010). Metabolic vulnerability disposes retinal ganglion cell axons to dysfunction in a model of glaucomatous degeneration. J. Neurosci. 30, 5644-5652. doi: 10.1523/JNEUROSCI.5956-09.2010

Benraiss, A., Wang, S., Herrlinger, S., Li, X., Chandler-Militello, D., Mauceri, J., et al. (2016). Human glia can both induce and rescue aspects of disease phenotype in Huntington disease. Nat. Commun. 7:11758. doi: $10.1038 /$ ncomms11758

Bleckert, A., Schwartz, G. W., Turner, M. H., Rieke, F., and Wong, R. O. (2014). Visual space is represented by nonmatching topographies of distinct mouse retinal ganglion cell types. Curr. Biol. 24, 310-315. doi: 10.1016/j.cub.2013. 12.020

Boiko, T., Van Wart, A., Caldwell, J. H., Levinson, S. R., Trimmer, J. S., and Matthews, G. (2003). Functional specialization of the axon initial segment by isoform-specific sodium channel targeting. J. Neurosci. 23, 2306-2313. doi: 10.1523/JNEUROSCI.23-06-02306.2003
2015; Inman and Harun-Or-Rashid, 2017; Cooper et al., 2020), the additional burden enhanced excitability places on axons already challenged by limited bioenergetic resources may serve to tip the balance towards degeneration. In this sense, the phenomenon of enhanced excitability could represent both a pro-survival strategy from the standpoint of an individual RGC axon but a pro-degenerative factor for the optic projection.

\section{DATA AVAILABILITY STATEMENT}

The raw data supporting the conclusions of this article will be made available by the authors, without undue reservation.

\section{ETHICS STATEMENT}

The animal study was reviewed and approved by the Vanderbilt University Medical Center Institutional Animal Care and Use Committee.

\section{AUTHOR CONTRIBUTIONS}

$\mathrm{MR}, \mathrm{NM}$, and DC designed the research. MR, NM, and SP performed the research. MR, NM, AB, and DC analyzed the data. $\mathrm{MR}, \mathrm{NM}$, and DC wrote the aticle. All authors contributed to the article and approved the submitted version.

\section{FUNDING}

This research was supported by a departmental unrestricted award by the Research to Prevent Blindness Inc., Research to Prevent Blindness Inc. Stein Innovation Award, the Stanley Cohen Innovation Fund, and National Institutes of Health (NIH) grants EY017427, EY024997, and EY008126 to DC. Imaging supported through the Vanderbilt University Medical Center Cell Imaging Shared Resource core facility and NIH grants CA68485, DK20593, DK58404, and DK59637.

Bouskila, J., Micaelo-Fernandes, C., Palmour, R. M., Bouchard, J.-F., and Ptito, M. (2020). Transient receptor potential vanilloid type 1 is expressed in the horizontal pathway of the vervet monkey retina. Sci. Rep. 10:12116. doi: 10.1038/s41598-020-68937-9

Caldwell, J. H., Schaller, K. L., Lasher, R. S., Peles, E., and Levinson, S. R. (2000). Sodium channel $\mathrm{Na}_{v} 1.6$ is localized at nodes of ranvier, dendrites, and synapses. Proc. Natl. Acad. Sci. U S A 97, 5616-5620. doi: 10.1073/pnas.090 034797

Calkins, D. J. (2012). Critical pathogenic events underlying progression of neurodegeneration in glaucoma. Prog. Retin. Eye Res. 31, 702-719. doi: 10.1016/j.preteyeres.2012.07.001

Caterina, M. J., Leffler, A., Malmberg, A. B., Martin, W. J., Trafton, J., PetersenZeitz, K. R., et al. (2000). Impaired nociception and pain sensation in mice lacking the capsaicin receptor. Science 288, 306-313. doi: 10.1126/science.288. 5464.306

Cazade, M., Bidaud, I., Lory, P., and Chemin, J. (2017). Activity-dependent regulation of T-type calcium channels by submembrane calcium ions. eLife 6:e22331. doi: 10.7554/eLife.22331

Choi, S. W. (2016). Life is lognormal! What to do when your data does not follow a normal distribution. Anaesthesia 71, 1363-1366. doi: 10.1111/anae. 13666 
Coleman, M. (2005). Axon degeneration mechanisms: commonality amid diversity. Nat. Rev. Neurosci. 6, 889-898. doi: 10.1038/nrn1788

Collard, J. F., Côté, F., and Julien, J. P. (1995). Defective axonal transport in a transgenic mouse model of amyotrophic lateral sclerosis. Nature 375, 61-64. doi: 10.1038/375061a0

Coombs, J., van der List, D., Wang, G.-Y., and Chalupa, L. M. (2006). Morphological properties of mouse retinal ganglion cells. Neuroscience 140, 123-136. doi: 10.1016/j.neuroscience.2006.02.079

Cooper, M. L., Pasini, S., Lambert, W. S., D'Alessandro, K. B., Yao, V., Risner, M. L., et al. (2020). Redistribution of metabolic resources through astrocyte networks mitigates neurodegenerative stress. Proc. Natl. Acad. Sci. U S A 117, 18810-18821. doi: 10.1073/pnas.2009425117

Coughlin, L., Morrison, R. S., Horner, P. J., and Inman, D. M. (2015). Mitochondrial morphology differences and mitophagy deficit in murine glaucomatous optic nerve. Invest. Ophthalmol. Vis. Sci. 56, 1437-1446. doi: $10.1167 /$ iovs. $14-16126$

Crish, S. D., Sappington, R. M., Inman, D. M., Horner, P. J., and Calkins, D. J. (2010). Distal axonopathy with structural persistence in glaucomatous neurodegeneration. Proc. Natl. Acad. Sci. U S A 107, 5196-5201. doi: 10.1073/pnas.0913141107

Della Santina, L., Inman, D. M., Lupien, C. B., Horner, P. J., and Wong, R. O. (2013). Differential progression of structural and functional alterations in distinct retinal ganglion cell types in a mouse model of glaucoma. J. Neurosci. 33, 17444-17457. doi: 10.1523/JNEUROSCI.546112.2013

Dickerson, B. C., Salat, D. H., Greve, D. N., Chua, E. F., Rand-Giovannetti, E., Rentz, D. M., et al. (2005). Increased hippocampal activation in mild cognitive impairment compared to normal aging and AD. Neurology 65, 404-411. doi: 10.1212/01.wnl.0000171450.97464.49

El-Danaf, R. N., and Huberman, A. D. (2015). Characteristic patterns of dendritic remodeling in early-stage glaucoma: evidence from genetically identified retinal ganglion cell types. J. Neurosci. 35, 2329-2343. doi: 10.1523/JNEUROSCI.141914.2015

Euler, T., Haverkamp, S., Schubert, T., and Baden, T. (2014). Retinal bipolar cells: elementary building blocks of vision. Nat. Rev. Neurosci. 15, 507-519. doi: $10.1038 / \mathrm{nrn} 3783$

Fogarty, M. J. (2018). Driven to decay: excitability and synaptic abnormalities in amyotrophic lateral sclerosis. Brain Res. Bull. 140, 318-333. doi: 10.1016/j. brainresbull.2018.05.023

Gibson, H. E., Edwards, J. G., Page, R. S., Van Hook, M. J., and Kauer, J. A. (2008). TRPV1 channels mediate long-term depression at synapses on hippocampal interneurons. Neuron 57, 746-759. doi: 10.1016/j.neuron.2007.12.027

Goswami, C., Dreger, M., Otto, H., Schwappach, B., and Hucho, F. (2006). Rapid disassembly of dynamic microtubules upon activation of the capsaicin receptor TRPV1. J. Neurochem. 96, 254-266. doi: 10.1111/j.1471-4159.2005.03551.x

Her, L.-S., and Goldstein, L. S. B. (2008). Enhanced sensitivity of striatal neurons to axonal transport defects induced by mutant huntingtin. J. Neurosci. 28, 13662-13672. doi: 10.1523/JNEUROSCI.4144-08.2008

Hu, W., Tian, C., Li, T., Yang, M., Hou, H., and Shu, Y. (2009). Distinct contributions of $\mathrm{Na}_{v} 1.6$ and $\mathrm{Na}_{v} 1.2$ in action potential initiation and backpropagation. Nat. Neurosci. 12, 996-1002. doi: 10.1038/nn.2359

Inman, D. M., and Harun-Or-Rashid, M. (2017). Metabolic vulnerability in the neurodegenerative disease glaucoma. Front. Neurosci. 11:146. doi: 10.3389/fnins.2017.00146

Jo, A. O., Noel, J. M., Lakk, M., Yarishkin, O., Ryskamp, D. A., Shibasaki, K., et al. (2017). Mouse retinal ganglion cell signalling is dynamically modulated through parallel anterograde activation of cannabinoid and vanilloid pathways. J. Physiol. 595, 6499-6516. doi: 10.1113/JP274562

Jones, R. C. III., Xu, L., and Gebhart, G. F. (2005). The mechanosensitivity of mouse colon afferent fibers and their sensitization by inflammatory mediators require transient receptor potential vanilloid 1 and acid-sensing ion channel 3 . J. Neurosci. 25, 10981-10989. doi: 10.1523/JNEUROSCI.0703-05.2005

Kalbaugh, T. L., Zhang, J., and Diamond, J. S. (2009). Coagonist release modulates NMDA receptor subtype contributions at synaptic inputs to retinal ganglion cells. J. Neurosci. 29, 1469-1479. doi: 10.1523/JNEUROSCI.4240-08.2009

Kernell, D. (1966). Input resistance, electrical excitability, and size of ventral horn cells in cat spinal cord. Science 152, 1637-1640. doi: 10.1126/science.152. 3729.1637
Kerrigan, T. L., Brown, J. T., and Randall, A. D. (2014). Characterization of altered intrinsic excitability in hippocampal CA1 pyramidal cells of the A $\beta$ overproducing PDAPP mouse. Neuropharmacology 79, 515-524. doi: 10.1016/j. neuropharm.2013.09.004

Khomula, E. V., Viatchenko-Karpinski, V. Y., Borisyuk, A. L., Duzhyy, D. E., Belan, P. V., and Voitenko, N. V. (2013). Specific functioning of Cav3.2 T-type calcium and TRPV1 channels under different types of STZ-diabetic neuropathy. Biochim. Biophys. Acta 1832, 636-649. doi: 10.1016/j.bbadis.2013. 01.017

Krieger, B., Qiao, M., Rousso, D. L., Sanes, J. R., and Meister, M. (2017). Four alpha ganglion cell types in mouse retina: function, structure, and molecular signatures. PLoS One 12:e0180091. doi: 10.1371/journal.pone.0180091

Lakk, M., Young, D., Baumann, J. M., Jo, A. O., Hu, H., and Krizaj, D. (2018). Polymodal TRPV1 and TRPV4 sensors colocalize but do not functionally interact in a subpopulation of mouse retinal ganglion cells. Front. Cell. Neurosci. 12:353. doi: 10.3389/fncel.2018.00353

Li, S.-H., and Li, X.-J. (2004). Huntingtin and its role in neuronal degeneration. Neuroscientist 10, 467-475. doi: 10.1177/1073858404266777

Liang, Z., and Freed, M. A. (2012). Cross inhibition from ON to OFF pathway improves the efficiency of contrast encoding in the mammalian retina. J. Neurophysiol. 108, 2679-2688. doi: 10.1152/jn.00589.2012

Margolis, D. J., and Detwiler, P. B. (2007). Different mechanisms generate maintained activity in $\mathrm{ON}$ and OFF retinal ganglion cells. J. Neurosci. 27, 5994-6005. doi: 10.1523/JNEUROSCI.0130-07.2007

Margolis, D. J., Gartland, A. J., Euler, T., and Detwiler, P. B. (2010). Dendritic calcium signaling in $\mathrm{ON}$ and OFF mouse retinal ganglion cells. J. Neurosci. 30, 7127-7138. doi: 10.1523/JNEUROSCI.5694-09.2010

McGrady, N. R., Risner, M. L., Vest, V., and Calkins, D. J. (2020). TRPV1 tunes optic nerve axon excitability in glaucoma. Front. Physiol. 11:249. doi: $10.3389 /$ fphys.2020.00249

Mitra, P., and Miller, R. F. (2007). Normal and rebound impulse firing in retinal ganglion cells. Vis. Neurosci. 24, 79-90. doi: 10.1017/S0952523807070101

Morfini, G. A., Burns, M., Binder, L. I., Kanaan, N. M., LaPointe, N., Bosco, D. A., et al. (2009). Axonal transport defects in neurodegenerative diseases. J. Neurosci. 29, 12776-12786. doi: 10.1523/JNEUROSCI.3463-09.2009

Ou, Y., Jo, R. E., Ullian, E. M., Wong, R. O., and Della Santina, L. (2016). Selective vulnerability of specific retinal ganglion cell types and synapses after transient ocular hypertension. J. Neurosci. 36, 9240-9252. doi: 10.1523/JNEUROSCI. 0940-16.2016

Palop, J. J., and Mucke, L. (2016). Network abnormalities and interneuron dysfunction in Alzheimer disease. Nat. Rev. Neurosci. 17, 777-792. doi: 10.1038/nrn.2016.141

Pang, J.-J., Gao, F., and Wu, S. M. (2003). Light-evoked excitatory and inhibitory synaptic inputs to $\mathrm{ON}$ and $\mathrm{OFF}$ alpha ganglion cells in the mouse retina. J. Neurosci. 23, 6063-6073. doi: 10.1523/JNEUROSCI.23-14-06063.2003

Ren, X., Roessler, A. E., Lynch, T. L. L. IV., Haar, L., Mallick, F., Lui, Y., et al. (2019). Cardioprotection via the skin: nociceptor-induced conditioning against cardiac MI in the NIC of time. 316, H543-H553. doi: 10.1152/ajpheart. 00094.2018

Risner, M. L., McGrady, N. R., Pasini, S., Lambert, W. S., and Calkins, D. J. (2020). Elevated ocular pressure reduces voltage-gated sodium channel NaV1.2 protein expression in retinal ganglion cell axons. Exp. Eye Res. 190:107873. doi: 10.1016/j.exer.2019.107873

Risner, M. L., Pasini, S., Cooper, M. L., Lambert, W. S., and Calkins, D. J. (2018). Axogenic mechanism enhances retinal ganglion cell excitability during early progression in glaucoma. Proc. Natl. Acad. Sci. U S A 115, E2393-E2402. doi: $10.1073 /$ pnas. 1714888115

Rong, W., Hillsley, K., Davis, J. B., Hicks, G., Winchester, W. J., and Grundy, D. (2004). Jejunal afferent nerve sensitivity in wild-type and TRPV1 knockout mice. J. Physiol. 560, 867-881. doi: 10.1113/jphysiol.2004.071746

Rush, A. M., Dib-Hajj, S. D., and Waxman, S. G. (2005). Electrophysiological properties of two axonal sodium channels, $\mathrm{Na}_{\mathrm{v}} 1.2$ and $\mathrm{Na}_{\mathrm{v}} 1.6$, expressed in mouse spinal sensory neurones. J. Physiol. 564, 803-815. doi: 10.1113/jphysiol. 2005.083089

Sanchez, P. E., Zhu, L., Verret, L., Vossel, K. A., Orr, A. G., Cirrito, J. R., et al. (2012). Levetiracetam suppresses neuronal network dysfunction and reverses synaptic and cognitive deficits in an Alzheimer's disease model. Proc. Natl. Acad. Sci. U S A 109, E2895-E2903. doi: 10.1073/pnas.1121081109 
Sappington, R. M., Sidorova, T., Long, D. J., and Calkins, D. J. (2009). TRPV1: contribution to retinal ganglion cell apoptosis and increased intracellular $\mathrm{Ca}^{2+}$ with exposure to hydrostatic pressure. Invest. Ophthalmol. Vis. Sci. 50, 717-728. doi: 10.1167/iovs.08-2321

Sappington, R. M., Sidorova, T., Ward, N. J., Chakravarthy, R., Ho, K. W., and Calkins, D. J. (2015). Activation of transient receptor potential vanilloid-1 (TRPV1) influences how retinal ganglion cell neurons respond to pressurerelated stress. Channels 9, 102-113. doi: 10.1080/19336950.2015.1009272

Schmidt, T. M., Alam, N. M., Chen, S., Kofuji, P., Li, W., Prusky, G. T., et al. (2014). A role for melanopsin in alpha retinal ganglion cells and contrast detection. Neuron 82, 781-788. doi: 10.1016/j.neuron.2014.03.022

Scotland, R. S., Chauhan, S., Davis, C., De Felipe, C., Hunt, S., Kabir, J., et al. (2004). Vanilloid receptor TRPV1, sensory C-fibers, and vascular autoregulation: a novel mechanism involved in myogenic constriction. Circ. Res. 95, 1027-1034. doi: 10.1161/01.RES.0000148633.93110.24

Stanford, K. R., Hadley, S. H., Barannikov, I., Ajmo, J. M., Bahia, P. K., and Taylor-Clark, T. E. (2019). Antimycin A-induced mitochondrial dysfunction activates vagal sensory neurons via ROS-dependent activation of TRPAl and ROS-independent activation of TRPV1. Brain Res. 1715, 94-105. doi: 10.1016/j. brainres.2019.03.029

Stokin, G. B., Lillo, C., Falzone, T. L., Brusch, R. G., Rockenstein, E., Mount, S. L., et al. (2005). Axonopathy and transport deficits early in the pathogenesis of Alzheimer's disease. Science 307, 1282-1288. doi: 10.1126/science.1105681

Sullivan, S. J., and Miller, R. F. (2012). AMPA receptor-dependent, light-evoked D-serine release acts on retinal ganglion cell NMDA receptors. J. Neurophysiol. 108, 1044-1051. doi: 10.1152/jn.00264.2012

Tham, Y.-C., Li, X., Wong, T. Y., Quigley, H. A., Aung, T., and Cheng, C.-Y. (2014). Global prevalence of glaucoma and projections of glaucoma burden through 2040: a systematic review and meta-analysis. Ophthalmology 121, 2081-2090. doi: 10.1016/j.ophtha.2014.05.013

van Zundert, B., Peuscher, M. H., Hynynen, M., Chen, A., Neve, R. L., Brown, R. H. Jr., et al. (2008). Neonatal neuronal circuitry shows hyperexcitable disturbance in a mouse model of the adult-onset neurodegenerative disease amyotrophic lateral sclerosis. J. Neurosci. 28, 10864-10874. doi: 10.1523/JNEUROSCI.134008.2008

Vriens, J., Appendino, G., and Nilius, B. (2009). Pharmacology of vanilloid transient receptor potential cation channels. Mol. Pharmacol. 75, 1262-1279. doi: 10.1124/mol.109.055624

Ward, N. J., Ho, K. W., Lambert, W. S., Weitlauf, C., and Calkins, D. J. (2014). Absence of transient receptor potential vanilloid-1 accelerates stressinduced axonopathy in the optic projection. J. Neurosci. 34, 3161-3170. doi: 10.1523/JNEUROSCI.4089-13.2014

Wässle, H. (2004). Parallel processing in the mammalian retina. Nat. Rev. Neurosci. 5, 747-757. doi: 10.1038/nrn1497

Weitlauf, C., Ward, N. J., Lambert, W. S., Sidorova, T. N., Ho, K. W., Sappington, R. M., et al. (2014). Short-term increases in transient receptor potential vanilloid-1 mediate stress-induced enhancement of neuronal excitation. J. Neurosci. 34, 15369-15381. doi: 10.1523/JNEUROSCI.3424 $-14.2014$

Werginz, P., Raghuram, V., and Fried, S. I. (2020). Tailoring of the axon initial segment shapes the conversion of synaptic inputs into spiking output in OFF- $\alpha$ T retinal ganglion cells. Sci. Adv. 6:eabb6642. doi: 10.1126/sciadv.abb6642

Conflict of Interest: The authors declare that the research was conducted in the absence of any commercial or financial relationships that could be construed as a potential conflict of interest.

Copyright (C) 2021 Risner, McGrady, Boal, Pasini and Calkins. This is an open-access article distributed under the terms of the Creative Commons Attribution License (CC BY). The use, distribution or reproduction in other forums is permitted, provided the original author(s) and the copyright owner(s) are credited and that the original publication in this journal is cited, in accordance with accepted academic practice. No use, distribution or reproduction is permitted which does not comply with these terms. 